\title{
Sub-surface hotspots in shallow seas: fine-scale limited locations of top predator foraging habitat indicated by tidal mixing and sub-surface chlorophyll
}

\author{
B. E. Scott ${ }^{1, *}$, J. Sharples ${ }^{2}$, O. N. Ross ${ }^{3}$, J. Wang ${ }^{1}$, G. J. Pierce ${ }^{1,4}$, C. J. Camphuysen ${ }^{5}$ \\ ${ }^{1}$ School of Biological Sciences, Institute of Biological and Environmental Sciences University of Aberdeen, \\ Tillydrone Avenue, Aberdeen, AB24 2TZ, UK \\ ${ }^{2}$ Proudman Oceanographic Laboratory, Joseph Proudman Building, 6 Brownlow Street, University of Liverpool, \\ Liverpool, L3 5DA, UK \\ ${ }^{3}$ Mediterranean Centre for Marine and Environmental Research, (CMIMA, CSIC), Marine Technology Unit (UTM), \\ Pg. Marítim de la Barceloneta, 37-49, 08003 Barcelona, Spain \\ ${ }^{4}$ Instituto Español de Oceanografía, Centro Oceanográfico de Vigo, PO Box 1552, 36200 Vigo, España \\ ${ }^{5}$ Royal Netherlands Institute for Sea Research, PO Box 59, 1790 AB Den Burg, Texel, The Netherlands
}

\begin{abstract}
The foraging habitats of 7 species of marine apex predators were observed simultaneously in a shallow sea, with continuous measurements taken of the detailed bio-physical water column characteristics to determine habitat preferences. We found the occurrence of small-scale 'hotspots', where $50 \%$ of all animals were actively foraging in less than $5 \%$ of the $1000 \mathrm{~km}$ of transects surveyed. By investigating a contrasting range of foraging strategies across a variety of fisheating seabirds and marine mammals, we determined which habitat characteristics were consistently important across species. A static habitat variable, tidal stratification, $\log _{10}\left(h / U^{3}\right)(h=$ water depth, $U=$ tidal current amplitude), was found to be the best indicator of the probability of presence and abundance of individual species. All 7 mobile top-predators preferentially foraged within habitats with small-scale (2 to $10 \mathrm{~km}$ ) patches having (1) high concentrations of chlorophyll in the sub-surface chlorophyll maximum $\left(C H L_{\max }\right)$ and (2) high variance in bottom topography, with different species preferring to forage in different locations within these habitats. Patchiness of $C H L_{\max }$ was not associated with the locations of strong horizontal temperature gradients (fronts) or high surface chlorophyll values, but instead may be related to areas of high sub-surface primary production due to locally increased vertical mixing. These small-scale areas represent a newly identified class of spatially important location that may play a critical role within the trophic coupling of shallow seas. Such subsurface hotspots may represent the limited locations where the majority of predator-prey interactions occur, despite making up only a small percentage of the marine environment.
\end{abstract}

KEY WORDS: Biological hotspots · Foraging habitats · Marine top predators · Predator-prey interactions $\cdot$ Shallow sea $\cdot$ Sub-surface chlorophyll maximum $\cdot$ Tidal mixing $\cdot$ Topography

\section{INTRODUCTION}

The foraging locations of marine piscivorous predators may be extremely limited spatially and temporally. Evidence increasingly indicates that marine mammals and seabirds use not only a small set of locations, but also a limited range of tidal conditions in which to cap- ture their fish prey (Uda 1952, Irons 1998, Simard et al. 2002, Johnston et al. 2005a, b, Bertrand et al. 2008, Stevick et al. 2008). The ecological implications are that the successful capture of prey by apex predators requires specific environmental conditions at a limited number of suitable locations; predators must be at 'the right place at the right time'. 
Review studies on the upwelling systems of the Pacific Ocean identified spatially and temporally predictable 'biological hotspots' with distinct surface signatures (Spear et al. 2001, Bakun 2006, Ballance et al. 2006, Sydeman et al. 2006). At this large scale, the mechanistic evidence behind the creation of hotspots for marine predator foraging points directly to both topographical features (Genin 2004, Yen et al. 2004) and primary productivity (Ware \& Thomson 2005, Bost et al. 2009). The general conclusion of many largescale studies is that seabirds and marine mammals are found preferentially foraging within different types of frontal region: areas of intersection between different water mass types where there are steep surface (horizontal) gradients in water density. Biological reasoning links foraging to frontal locations via the elevated levels of primary production and aggregation of planktonic organisms found at fronts (Pingree et al. 1975, Franks \& Chen 1996, Durazo et al. 1998, Russell et al. 1999, Lough and Manning 2001). However, some of the studies mentioned above stress the point that not all marine mammals and seabirds forage preferentially at the fronts (Ballance et al. 2006, Spear et al. 2001).

Sea surface temperature (SST) fronts and surface colour (calibrated for chlorophyll biomass) from satellite imagery are now widely used as proxies for locations of productivity and in the identification of potential foraging areas for marine predators over global scales (Polovina et al. 2001, Worm et al. 2005). However, a study off the west coast of North America has shown that SST is not always a reliable predictor of foraging habitat across a wide range of seabird species (Burger 2003). In this paper, we address the possibility that some important areas of foraging do not have oceanographic surface signatures, but are instead associated with (less observationally convenient) subsurface processes.

Understanding the links between a predator and its prey is challenging. We need to appreciate that predator-prey interactions may occur on a time scale of minutes and on spatial scales of tens of metres or less. The few studies directed at these smaller scales have been conducted in areas with very strong tidal currents. Tidal forcing has been found to be the main cause of prey aggregation at such locations (Decker \& Hunt 1996, Mendes et al. 2002, Cotté \& Simard 2005, Johnston et al. 2005a,b) and primary production has also been implicated as playing an important role in predator distribution (Ladd et al. 2005, Sinclair et al. 2005). Two recent studies, not within tidally active areas, have investigated predator-prey interactions across a range of trophic levels at the appropriate spatial and temporal scales (Bertrand et al. 2008, Stevick et al. 2008). In both cases, internal wave activity was indi- cated as a potential mechanism for increased predatorprey interaction; a mechanism that our study also points towards. However, these studies were based on locations where there were large changes in topography (>100 m differences), located near shelf edges and which had obvious surface features (temperature gradients, large surface slicks) defining the regions of predictable predator foraging.

In this study, we worked in a shallow sea region $(<200 \mathrm{~m})$ with limited tidal speeds $\left(<1.0 \mathrm{~m} \mathrm{~s}^{-1}\right)$ and minimal differences in topographical features $(<30 \mathrm{~m}$ differences in bottom depth). We define the foraging habitats for a range of top predators by collecting continuous and simultaneous information on both (1) the distribution of foraging animals and (2) detailed horizontal and vertical structure of the water column in which animals were actively foraging. Our approach was to collect and compare information from 7 species with contrasting foraging behaviours (common guillemot, northern gannet, black-legged kittiwake, minke whale, harbour porpoise, white-beaked dolphin and grey seal) and to explore not only the expected differences in foraging habitats, but also to search for any similarities across species. We present evidence for the extreme patchiness of foraging hotspots, well away from frontal locations or from regions with high surface chlorophyll biomass. These findings have important consequences for defining top-predator foraging habitat within shallow seas.

\section{MATERIALS AND METHODS}

Study area. The study area, covering approximately $100 \times 100 \mathrm{~km}$, is in the North Sea off the east coast of Scotland, UK. Eight transects across the area, approximately $10 \mathrm{~km}$ apart, were carried out from 8 to 19 June 2003 (see Fig. 1) on a 66 m Netherlands Institute for Sea Research vessel, the 'Pelagia'. The direction of transects alternated between E-W and W-E and daily starting locations were driven only by the location of stoppage the day before, such that time of day and location were randomly sampled. Trained observers continuously recorded the abundance and behaviour of seabirds and marine mammals from a platform approximately $20 \mathrm{~m}$ above sea level. The resulting indices of animal presence, absence and abundance are used as response variables: i.e. those variables for which we wish to explain the variation in distribution in terms of oceanographic factors. The biophysical characteristics of the entire water column were continuously sampled via an undulating ScanFish (MKII 1250, EIVA) carrying a Sea-Bird 911 CTD and Chelsea Instruments Aquatracka MKIII chlorophyll fluorometer. Oceanographic characteristics are used as the explana- 
tory variables in determining the defining habitat characteristics for individual species, as well as for identifying common habitat variables for a group of 7 representative top-predator species.

Census of seabirds and marine mammals. The striptransect techniques deployed to count seabirds and marine mammals were those that have been developed as the standard for ship-based seabird surveys in the North Sea (Tasker et al. 1984, Buckland et al. 2001, Camphuysen et al. 2004). Seabirds and marine mammals were counted in 5 min intervals within a strip $300 \mathrm{~m}$ ahead and $300 \mathrm{~m}$ to one side of the vessel (the side being chosen to select the best light conditions). A minimum of 2 observers were active at all times, with a third observer normally accompanying most observations. The use of 5 different distance bands within and just beyond the strip allowed for corrections for missed birds and cetaceans; ranges are referred to as A (0-50 m), B (50-100 m), C (100-200 m), D (200-300 m) and $E$ (beyond $300 \mathrm{~m}$ and outside transect). The ship travelled at a constant speed of approximately 8 knots $\left(4.1 \mathrm{~m} \mathrm{~s}^{-1}\right)$, such that each 5 min interval covered an average of $1.24 \mathrm{~km}$. In addition to the standard techniques, and to be able to discriminate between feeding or foraging birds from non-feeding individuals (e.g. Ashmole 1971), 20 types of feeding behaviour and 16 types of non-feeding behaviour were recorded (details in Camphuysen \& Garthe 2004: see our Table 1). Birds associated with, or apparently attracted by, the research vessel were not used for calculations.

Seven representative species were chosen from the observed range of 27 species for use in this study, based on the most abundant seabird and marine mammal species and representing a range of different foraging strategies. The 7 species were the common guillemot Uria aalge, northern gannet Morus bassanus, black-legged kittiwake Rissa tridactyla, minke whale Balaenoptera acutorostrata, harbour porpoise Phocoena phocoena, white-beaked dolphin Lagenorhynchus albirostris and the grey seal Halichoerus grypus (see Table 1 for a description of their different foraging methods).

The abundance and presence of animals in each 5 min bin was used to explore explanatory habitat variables for each individual species. In order to investigate possible common foraging habitat preferences, the 7 species were also grouped together under 2 separate definitions of total abundance: the first index of abundance was simply the total number of animals seen foraging per 5 min bin; the second index of abundance included a transformation of animal counts for more conservative multi-species comparisons. Smaller, more numerous animals can potentially dominate abundance estimates. However, larger animals, although much less numerous, require a proportionally greater prey abundance and therefore represent a greater foraging presence. To begin to correct for this size/ number bias, the number of individuals per species and per observation was multiplied by the body mass of that species. The mean species mass used for this transformation of animal counts is averaged between males and females (where available) and between the lower and higher published values (see Table 1). Due to the order of magnitude difference in size between marine mammals and seabirds, the $\log _{10}$ of the mean weight $(\bar{W}) \times$ the abundance $\left(A_{t}+1\right)$ of each species was calculated, summed for each 5 min bin and used as an index of total animal biomass abundance $A_{T}$ :

$$
A_{T}=\sum_{t=t_{0}}^{t_{0}+\Delta t} \log _{10}\left[\bar{w}\left(A_{t}+1\right)\right]
$$

where $\Delta t=5 \mathrm{~min}$. This index of total biomass abundance decreases the influence of numerous small animals of a single species. The transformation also increases the importance of multi-species presence in any one $5 \mathrm{~min}$ bin observation.

Physical and biological oceanographic variables from ScanFish data. The sampling of physical features of the water column was carried out with the ScanFish, such that continuous vertical and horizontal information on temperature, salinity, density and fluorescence (a proxy for the abundance of chlorophyll) was collected to within 2 to $5 \mathrm{~m}$ of both the sea bed and the surface. Data were sampled at $1.0 \mathrm{~s}$ intervals, yielding a vertical resolution of between 0.5 to $1.0 \mathrm{~m}$. With the maximum depth of the study area being less than $90 \mathrm{~m}$ and the speed of towing being a constant 8 knots $\left(4.1 \mathrm{~m} \mathrm{~s}^{-1}\right)$, the horizontal distance between the midpoint of up and down casts of the ScanFish was never more than $400 \mathrm{~m}$ (generally ranging between 200 and $300 \mathrm{~m}$ ). In order to compare the continuous physical water column characteristics measured by the ScanFish to the 5 min bin observations of visible top-predators, summaries of physical and biological characteristics of the water column were created for the same observational 5 min bins. Most 5 min bins represent a horizontal travel distance of approximately $1.24 \mathrm{~km}$. There is a small level of variation in the distance travelled every 5 min due to slight variations in ship speed, but this does not affect the analysis or results because these variations affect both physical data and seabird counts in the same way.

Degree of water column stratification: The difference between surface and bottom temperature (or density) produces an index of how well the water column is mixed or stratified (see Fig. 1). This assumption breaks down as we approach the mouth of the Firth of Forth, where the density stratification is mainly caused by differences in salinity. Stratification is a useful physical proxy for a range of biological characteristics, such 
as the likely community of phytoplankton and zooplankton species and the type of food web (i.e. short versus microbial food webs: Cushing 1975). Away from the coast and regions of freshwater influence, the main factors forcing the strength of stratification are seasonal and daily variations in solar heating, wind-driven surface mixing, and tidally-driven bottom mixing. In order to filter out much of the diurnal fluctuations in stratification, we used the mean temperature and density above and below the pycnocline over each $5 \mathrm{~min}$ bin to produce variables for thermal stratification $(\Delta T)$ and density stratification $(\Delta \rho)$. The location of the top and bottom of the pycnocline were defined as the depths at which the vertical density gradient dropped below $0.01 \mathrm{~kg} \mathrm{~m}^{-4}$. We also produced estimates of the average temperature and density gradients $\left(\overline{\Delta T / z_{p}}\right.$, $\left.\overline{\Delta \rho / z_{\mathrm{p}}}\right)$ across the width of the pycnocline $\left(z_{\mathrm{p}}\right)$ for each 5 min bin.

Chlorophyll concentrations: The voltage output from the fluorometer on the ScanFish was used for all statistical analyses and generalised additive model (GAM) graphical output. The fluorometer output was calibrated to chlorophyll concentration $\left(\mathrm{mg} \mathrm{m}^{-3}\right)$ using chlorophyll samples taken over a representative range of depths and locations across the study area in the form of $C H L=a \times$ voltage $^{b}$. This yielded a calibration equation of: $C H L\left[\mathrm{mg} \mathrm{m}^{-3}\right]=19.85 \times$ voltage $^{1.91}(\mathrm{SE}$ : $a= \pm 4.677, b= \pm 0.187 ; \mathrm{n}=70$ ). Fluorometer chlorophyll concentrations were averaged over all data collected within each $5 \mathrm{~min}$ bin to produce mean chlorophyll levels per bin $\left(\overline{C H L}_{i}\right.$ see Fig. 2a). Values for the sub-surface chlorophyll maximum $\left(C H L_{\max }\right)$ : see Fig. 2b) were defined as the highest concentration of chlorophyll within each 5 min bin of observations, regardless of where they occurred vertically in the water column (note that all but 2 values were deeper than $5 \mathrm{~m}$ and the median depth was $15.6 \mathrm{~m}$ ). All observations were taken during daylight hours (04:00 to 20:00 h GMT).

Seastate and time of day: Rough sea state (Seastate) will decrease the chances of visual detection of marine animals, and time of day (Time) can also affect the presence, absence and abundance of many animals; both were therefore tested as explanatory variables.

Static oceanographic variables. The oceanographic variables defined above are those that were collected simultaneously with the animal data. They have the potential to vary due to local and seasonal forcing, and represent the state of the environment which has resulted from recent meteorological and tidal variability. However, we also need to consider variables unaffected by inter-annual and shorter timescale variability. This will allow the results from this study to be compared to other years and other bird and mammal foraging locations, as well as determining whether predators are using a long-term geographical decision rather than responding to short-term events. We therefore produce static explanatory habitat variables that are described below.

Potential for seasonal thermal stratification $\left(h / U^{3}\right)$ : In shallow seas $(<200 \mathrm{~m})$ the tendency of a water column to thermally stratify can be quantified by the ratio between the total depth $(h)$ and the cube of a measure of the tidal current amplitude $(U), h / U^{3}$ (Simpson \& Hunter 1974, Pingree \& Griffiths 1978). Low values of $h / U^{3}$ indicate areas where the water column is likely to remain vertically mixed all year, while high values occur in areas that will thermally stratify during summer. Within stratifying regions, higher $h / U^{3}$ indicates stronger summer stratification. Values of what we have coined 'Tidal stratification', $\log _{10}\left(h / U^{3}\right)$, were calculated over the whole study area using depth data from the British Geological Society (BGS: www. bgs.ac.uk/products/digbath250/sample.html) and tidal velocities from the POLPRED tidal prediction model (Proudman Oceanographic Laboratory, NERC, UK). The tidal velocities used are the mean monthly depthmean tidal speeds for June 2003 and so represent average tidal speeds over 2 spring-neap cycles.

Depth and topographical data: The following potential habitat variables were derived from BGS data and extracted via GIS ArcView (ESRI) software derived at the $750 \mathrm{~m}$ radius scale for the location of each $5 \mathrm{~min}$ bin observation: maximum depth of the seabed $H_{\text {maxi }}$ mean depth of the seabed $\bar{H}_{\text {; }}$ standard deviation of depth

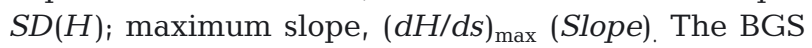
data were used rather than the shipboard depth data, as the variables could be derived from information in all directions rather than just the $\mathrm{E}-\mathrm{W}$ directions of the transects.

Analysis. One-way ANOVA and Tukey: Simultaneous multiple comparisons of the means of habitat variables, from the presence/absence and abundance data for the 7 species, were carried out using 1-way ANOVA and Tukey honestly significant difference (HSD) methods using S-Plus, version 7.0 (TIBCO).

Generalised additive models (GAMs): All potential explanatory variables were screened using histograms, dot plots (univariate), scatter plots (bivariate) and calculation of variance inflation factors (VIF) to determine distributions, detect outliers and identify co-linearity between variables. Where 2 variables were strongly collinear $(r \geq 0.8)$, one was excluded from further analysis. This occurred with the stratification indices for temperature and density as well as for 2 indices for thermal and density gradients, confirming that stratification in the study area was dominated by sea surface heat fluxes. Therefore only one variable was selected for each characteristic. Surface to bottom temperature difference $(\Delta \mathrm{T})$ was used to represent stratification. 
The density difference across the pycnocline was chosen to represent the indices for gradient $\left(\overline{\Delta \rho / z_{p}}\right)$. The maximum depth $\left(H_{\max }\right)$ and mean depth $(\bar{H})$ were highly correlated, as were slope and the variation in depth. Maximum depth $\left(H_{\max }\right)$ and depth variation $\mathrm{SD}(H)$ were kept as the explanatory variables. $\mathrm{SD}(H)$ was $\log$-transformed $\left(\log _{10}[S D(H)+1]\right)$. Seastate was treated as a continuous variable.

All response variables included a high proportion of zero values (absences) and so a 2-stage modelling strategy was used (Zuur et al. 2007). Presence was modelled using binomial GAM. Within a total of 800 observations, numbers of positive records (presence) for marine mammals ranged from 25 (white-beaked dolphins) to 35 (grey seal), with figures for seabirds ranging from 54 (gannet) to 363 (guillemot). For all marine mammals, the proportion of presence records is less than $5 \%$ which limited our ability to fit satisfactory models. For subsets of non-zero values of response variables, abundance (given presence) was also modelled with a GAM, fitted using appropriate distributions, normally a so-called quasi-Poisson (i.e. a Poisson distribution in which dispersion is not constrained, since the over-dispersion parameter for most models was >1). It should be noted that, for all the marine mammal species and for the gannet, observation sample sizes ranged from 25 to 54 ; since 9 explanatory variables were available, model results were treated with caution.

Explanatory variables were selected by repeated backward and forward selection; starting with full models, dropping out the least significant terms sequentially and building up from models with single explanatory variables. Cross-validation was used to estimate degrees of freedom for smoothers (the partial residual), although in all cases the maximum value was set to $3(\mathrm{k}=4)$ to avoid over-fitting. The final model selected in each case was that in which all terms were significant $(p<0.05)$ and which had the lowest value for Akaike's information criterion (AIC). Usually all criteria (AIC, deviance explained, significance of individual terms) were in agreement. Occasionally an explanatory variable would have a weak but significant effect ( $\mathrm{p}<$ 0.05) but its inclusion would increase the AIC score and reduce deviance explained; it was therefore dropped from the final model. In some cases no satisfactory fit could be achieved. All GAM analysis was carried out using Brodgar 2.5.6 (Highland Statistics) linked to R 2.6.0 (R Development Core Team).

\section{RESULTS}

\section{Physical and biological oceanographic data}

The location of the study area within the North Sea and the strength of stratification are presented in Fig. 1. There are obvious regions of higher stratification farther off the coast; however, the pattern is much more complex than a simple onshore/offshore divide. The northwestern corner of the study area, with the weakest stratification and highest tidal mixing, dominated as the location with the highest biomass of depthaveraged chlorophyll (Fig. 2a). However, the spatial patterns of locations of $C H L_{\max }$ (Fig. 2b) only occur in very limited areas within the more stratified region. They range in size from approximately $\sim 2$ to $10 \mathrm{~km}$ linear distance along the transects. The vast majority (91\%) of locations with $C H L_{\max }>2.0 \mathrm{mg} \mathrm{m}^{-3}$ were found well below the surface at depths $>10 \mathrm{~m}$ (median depth of $15.6 \mathrm{~m}$ ), indicating that their vertical locations

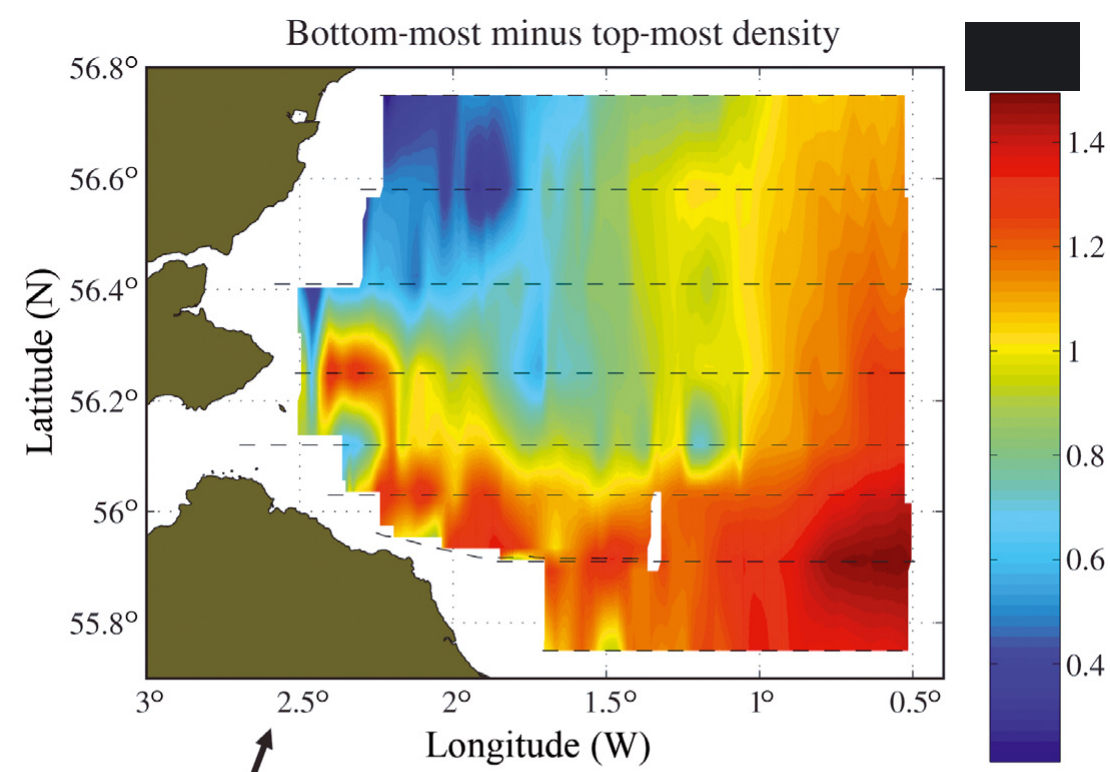

Fig. 1. Location of the study area in the North Sea and density stratification $(\Delta \rho)$ of the water column, shown here as the difference in density between $5 \mathrm{~m}$ of the surface and the bottom. The diagram was created using the continuous vertical temperature data collected by an undulating ScanFish (MKII) along $8 \mathrm{E}-\mathrm{W}$ transect lines (dashed lines) and is the equivalent of approximately 4000 single CTD casts. The data are continuous along the transect lines, but have been linearly interpolated to fill in the areas between the transect lines 
(a) Depth averaged chlorophyll

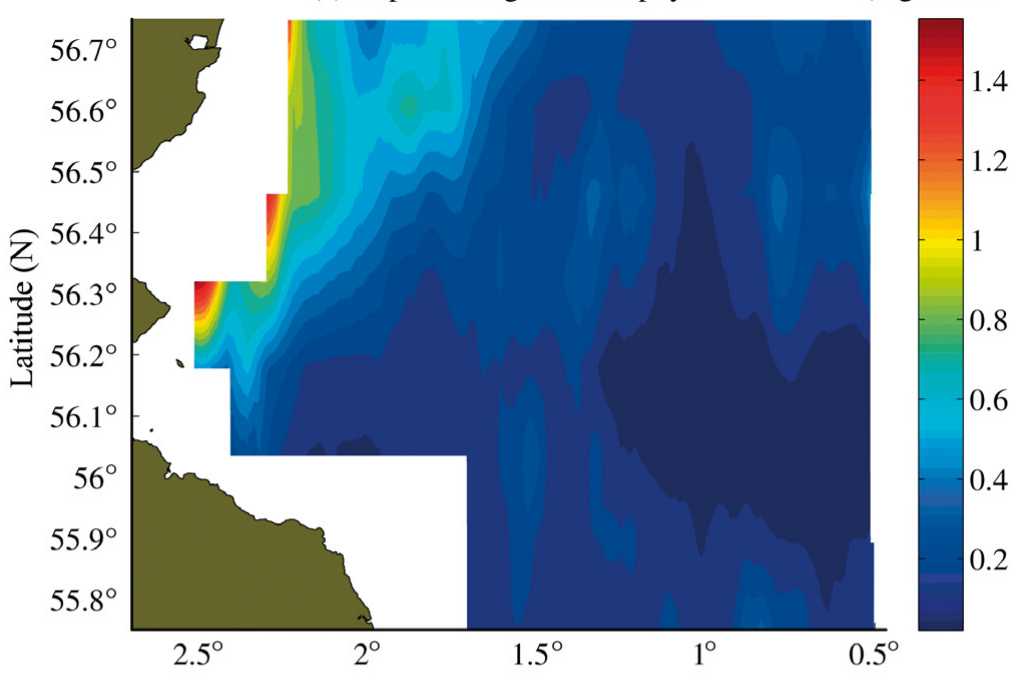

(b) Chlorophyll maximum

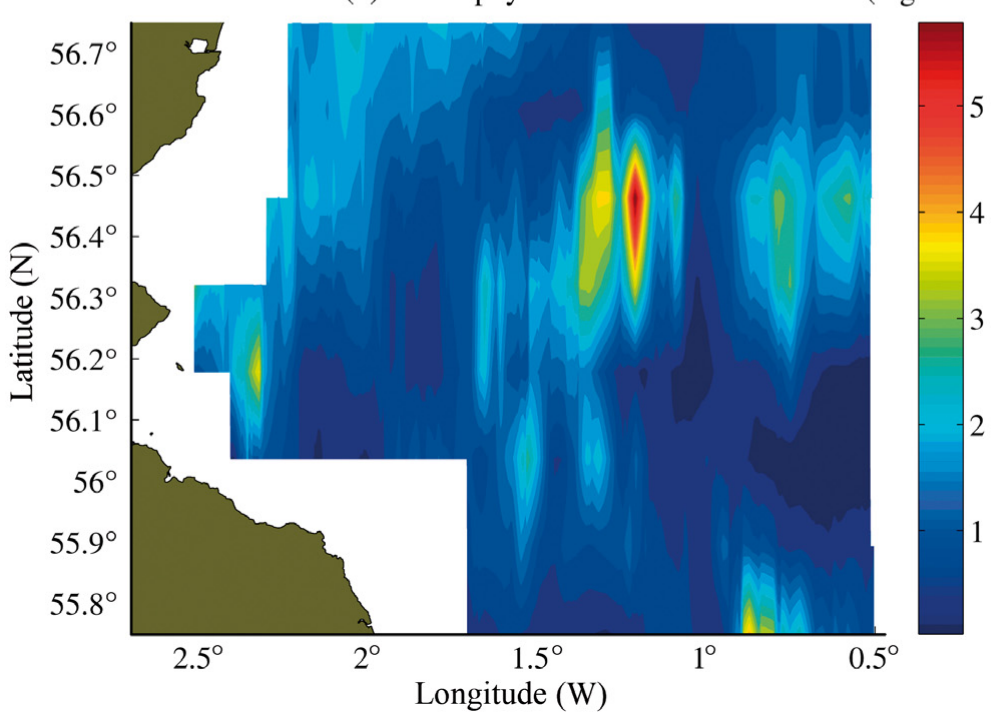

Fig. 2. Chlorophyll biomass values from continuous collection by a ScanFish (MKII) along the 8 transects used. As with Fig. 1, the values chlorophyll biomass, $\overline{C H L}\left(\mathrm{mg} \mathrm{m}^{-2}\right)$. (b) Maximum level of chlorophyll biomass, $C H L_{\max }\left(\mathrm{mg} \mathrm{m}^{-3}\right)$ found within the vertical water column within any one surface to bottom undulation of the ScanFish between the transects have been linearly interpolated. (a) Average

biweekly tidal currents; values between 2.75 and $3.5 \mathrm{~m}^{-2} \mathrm{~s}^{3}$ are regions likely to see spring-neap impacts on sub-surface primary production within the thermocline and that always remain stratified in summer (Sharples 2008). This implies that only a small fraction of the study site has areas (the far northwestern corner and a section at the centre of the southern section) that could be defined as frontal. The vast majority of the study area was stratified $\left(>1.0^{\circ} \mathrm{C}\right)$ and will always stratify in the summer as a result of surface heating overcoming mixing by tides. The 10 highest $\overline{C H L}$ values were found within a narrow range of $3.51<\log _{10}\left(h / U^{3}\right)<$ 3.59 whereas locations with $C H L_{\max }>$ $3.0 \mathrm{mg} \mathrm{m}^{-3}$ occurred only in areas with $\log _{10}\left(h / U^{3}\right)>3.55 \mathrm{~m}^{-2} \mathrm{~s}^{3}$. This suggests that these isolated locations of high $C H L_{\max }$ will occur in areas that can strongly stratify and that their existence has no link to fronts that are produced by tidal properties.

\section{Spatially limited foraging}

In total, 4847 animals of the 7 species in this study were observed foraging over $993 \mathrm{~km}$ of transect line coverage (Table 1 shows total numbers of each species observed). In $43 \%$ of all the 5 min bins surveyed, no animals were observed (Table 2). The majority of all animals (88\%) were found foraging in $25 \%$ of the $5 \mathrm{~min}$ bins along our transect lines. These figures are influenced by the presence of smaller, but much more numerous, birds. However, even when the abundance of all animals was viewed as a percentage of the total weighted biomass abundance (Eq. 1), $59 \%$ of foraging effort was still found within $25 \%$ of all the 5 min bins surveyed.

may be limited to within the thermocline. These locations would not be detected by sea-surface satellite colour imaging.

Values of $\log _{10}\left(h / U^{3}\right)$ for a larger region of the eastern North Sea are shown in Fig. 3, with the study area marked by the solid rectangle. A value of $2.75 \mathrm{~m}^{-2} \mathrm{~s}^{3}$ represents the locations of tidal fronts, separating permanently-mixed water from seasonally-stratified regions (Sharples 2008). Values between 2.3 and $2.75 \mathrm{~m}^{-2} \mathrm{~s}^{3}$ indicate regions that can switch between being mixed and stratified, depending on the phase of
The numbers of foraging animals observed were highly clumped: $50 \%$ of them were found in very limited locations, representing only $4.4 \%$ of the survey bins and containing at least 25 animals within any one 5 min bin (Table 1). However, these same areas of very high abundance (accounting for $50 \%$ of foraging animals by number) only make up $13.9 \%$ of the total weighted biomass abundance, suggesting the locations of highest abundances contain mostly single species and/or have extremely high numbers of smaller animals. 


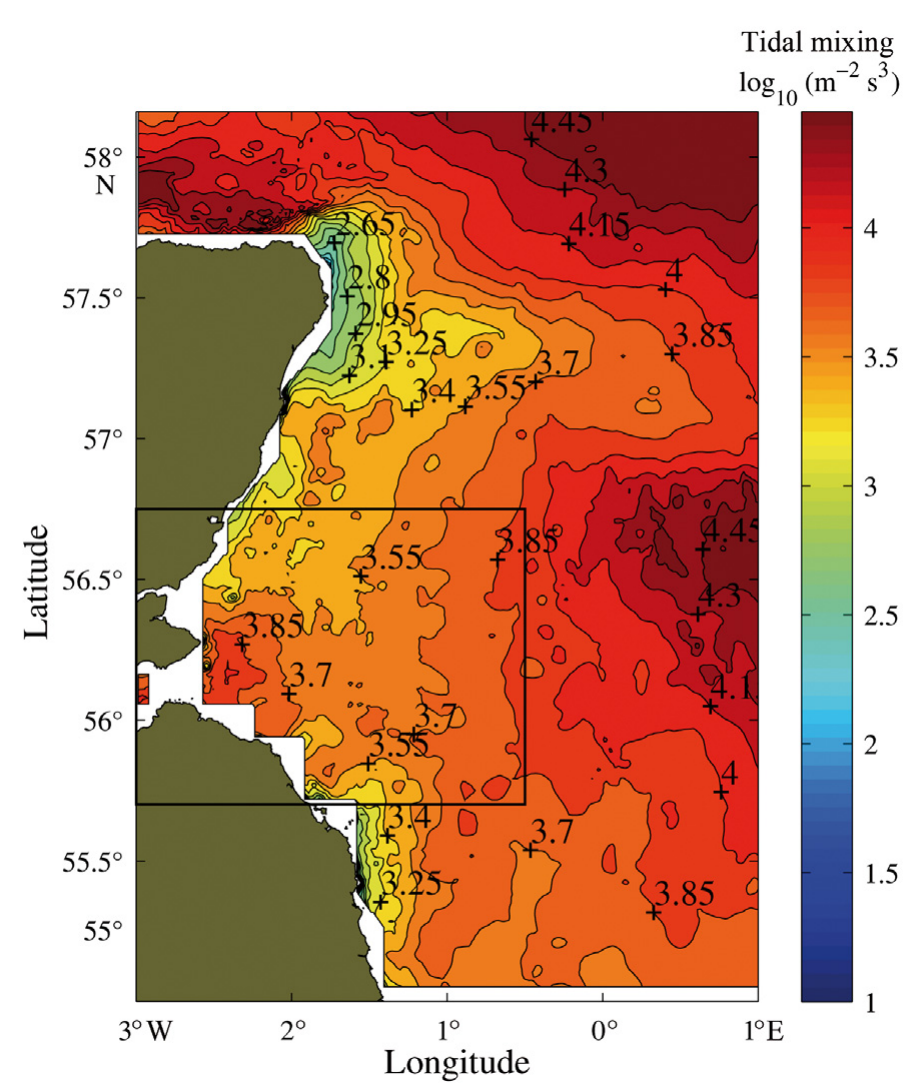

Fig. 3. Values of the tidal stratification variable, $\log _{10}\left(h / U^{3}\right)$, created from bottom depth $(h)$ and tidal speeds $\left(U^{3}\right)$. Data for a much larger region is presented to put the study area (within the box) into context

\section{Foraging habitat}

Single variables: differences and similarities between species

In this section we will first present the foraging habitat for each of the 7 species separately, then the foraging habitat commonalities across species. Because the different species of top-predators capture their prey using different foraging behaviours, one would expect that they may select different habitat types in which to forage. The mean values of the biological and physical explanatory variables at the locations in which each species was found (Table 3 ) indicate whether or not different species were targeting different habitats. Six out of 9 explanatory variables showed significant differences between the mean values for different species. The 3 variables which showed highly significant differences $(\mathrm{p}<0.0001)$ between species were $\Delta T, \log _{10}\left(h / U^{3}\right)$ and $\overline{C H L}$. The 3 variables which did not show differences between the species were $C H L_{\text {max }} S D(H)$ and Time.

The location and abundance of each species is mapped on top of $\Delta T, C H L_{\max }$ and $\log _{10}\left(h / U^{3}\right)$ for seabird (Fig. 4) and mammal species (Fig. 5). In general, there appears to be a preferred range of thermal stratification, with a dramatic drop of both presence and abundance for almost all species (except gannets and white-beaked dolphins: Figs. 4a \& $5 \mathrm{a}$, respectively), in the highly stratified waters farther offshore. This distribution might also be related to the distance from colonies in the case of seabirds and seals. The vast majority of foraging kittiwakes and minke whales were centred on longitude $1.5^{\circ} \mathrm{W}$, where the levels of $C H L_{\max }$ were high (Figs. 4b \& 5b, respectively). Guillemots were the most numerous species, with some obvious clusters found throughout most of the study area except in regions with higher values of $\log _{10}\left(h / U^{3}\right)$ (Fig. 4c).

In Fig. 6, we provide an example of the vertical $C H L_{\max }$ characteristics of the water column and compare the location values of the total weighted biomass abundances of all species with $C H L_{\max }$ and $\overline{C H L}$ along the representative middle transect (latitude: $56.25^{\circ} \mathrm{N}$ ). Fig. 6 clearly shows that, in combination, species seemed to be targeting areas with high $C H L_{\max }$ where there was little or no difference in $\overline{C H L}$.

We tested which species foraged in significantly different habitats from each other for the 3 variables which showed highly significant differences between species $\left[\log _{10}\left(h / U^{3}\right), \Delta T, \overline{C H L}\right]$ using Tukey's HSD (Fig. 7). Three pairs of species were found to forage in areas with significantly different values for all 3 variables (at the 95\% confidence level): white-beaked dolphins versus grey seals, gannet versus guillemot and gannet versus porpoise. An additional 5 pairs of species were found to forage in areas of significantly different values for 2 of the variables: white-beaked dolphins versus guillemot, whitebeaked dolphins versus harbour porpoise, gannet versus kittiwake, gannet versus grey seal and kittiwake versus grey seal. The species pair which was found in nearly exactly the same habitat across all 3 variables was kittiwake and minke whale. Additionally, 2 species pairs were found to have 2 variables with the same habitat value: white-beaked dolphins and gannet; porpoise and grey seal.

Comparing the mammals, harbour porpoises and grey seals were using very similar habitats with significantly lower values of $\log _{10}\left(h / U^{3}\right)$ and $\Delta T$ but higher $\overline{C H L}$ than for the minke whales and white-beaked dolphins. Comparing birds, kittiwakes and guillemots mainly shared the same habitat, with kittiwakes constantly in areas of higher $\log _{10}\left(h / U^{3}\right)$ and $\Delta T$ but lower $\overline{C H L}$ than guillemots. However, habitats used by both kittiwakes and guillemots were significantly different from those used by gannets, suggesting they do not forage in the more stratified water that only gannets 
Table 1. Average weight (and data source), foraging method and number of animals observed during the survey for each of the 7 species

\begin{tabular}{|c|c|c|c|c|c|}
\hline Species & $\begin{array}{l}\text { Avg. wt } \\
(\mathrm{kg})\end{array}$ & Foraging method & $\begin{array}{l}\text { List of foraging } \\
\text { behaviours }\end{array}$ & $\begin{array}{l}\text { Number of } \\
\text { nimals seen }\end{array}$ & Data source for Avg. wt \\
\hline $\begin{array}{l}\text { Guillemot } \\
\text { Uria aalge }\end{array}$ & 0.95 & Deep diving bird & $\begin{array}{l}\text { Holding fish } \\
\text { Pursuit diving } \\
\text { Actively searching }\end{array}$ & 3356 & http://blx1.bto.org/birdfacts/indexa_short.htm \\
\hline $\begin{array}{l}\text { Gannet } \\
\text { Morus bassanus }\end{array}$ & 3.0 & Plunge diving bird & $\begin{array}{l}\text { Scooping prey from } \\
\text { surface } \\
\text { Deep plunging } \\
\text { Shallow plunging } \\
\text { Pursuit diving }\end{array}$ & 568 & http://blx1.bto.org/birdfacts/indexa_short.htm \\
\hline $\begin{array}{l}\text { Kittiwake } \\
\text { Rissa tridactyla }\end{array}$ & 0.35 & Surface feeding bird & $\begin{array}{l}\text { Dipping } \\
\text { Surface seizing } \\
\text { Surface pecking } \\
\text { Deep plunging } \\
\text { Shallow plunging }\end{array}$ & 448 & http://blx1.bto.org/birdfacts/indexa_short.htm \\
\hline $\begin{array}{l}\text { Minke whale } \\
\text { Balaenoptera } \\
\text { acutorostrata }\end{array}$ & 6500 & $\begin{array}{l}\text { Individual shallow } \\
\text { diving whale }\end{array}$ & $\begin{array}{l}\text { Lunge-feeding (only } \\
\text { surface activities } \\
\text { could be logged) }\end{array}$ & y & www.whalecenter.org/species.htm \\
\hline $\begin{array}{l}\text { Harbour porpoise } \\
\text { Phocoena phocoena }\end{array}$ & 60 & $\begin{array}{l}\text { Group, fast speed } \\
\text { and pursuit }\end{array}$ & None specifically & 87 & http://marinebio.org/species.asp?id=364 \\
\hline $\begin{array}{l}\text { White-beaked dolphin } \\
\text { Lagenorhynchus } \\
\text { albirostris }\end{array}$ & 230 & $\begin{array}{l}\text { Group, fast speed and } \\
\text { pursuit, but much larger } \\
\text { than harbor porpoise }\end{array}$ & $\begin{array}{l}\text { Herding (only } \\
\text { surface activities } \\
\text { could be logged) }\end{array}$ & 104 & http://marinebio.org/species.asp?id=347 \\
\hline $\begin{array}{l}\text { Grey seal } \\
\text { Halichoerus grypus }\end{array}$ & 190 & $\begin{array}{l}\text { Diving, pursuit with the } \\
\text { ability to use flippers to } \\
\text { manipulate fish/sand }\end{array}$ & None specifically & 201 & http://marinebio.org/species.asp?id=300 \\
\hline
\end{tabular}

appear to utilise. Comparing birds and mammals, kittiwakes shared the same habitat as minke whales, but did not overlap with harbour porpoises and overlapped only slightly with grey seals. Guillemots overlapped with all other species except gannets, suggesting that they are generalist in their habitat preference but prefer water that is less strongly stratified. Compared to most other species except white-beaked dolphins, gannets foraged in water columns with a significantly higher $\log _{10}\left(h / U^{3}\right)$ and $\Delta T$, but a lower $\overline{C H L}$.

Table 2. Percentages of the surveyed area and corresponding percentages of the total number of foraging animals and total weighted biomass abundance of foraging animals in each category

\begin{tabular}{|lccc|}
\hline $\begin{array}{l}\text { Number of } \\
\text { animals per } \\
5 \text { min bin } \\
\text { observation }\end{array}$ & $\begin{array}{c}\text { Percentage of } \\
5 \text { min bins } \\
\text { surveyed } \\
(\%)\end{array}$ & $\begin{array}{c}\text { Percentage of } \\
\text { foraging } \\
\text { animals } \\
(\%)\end{array}$ & $\begin{array}{c}\text { Total } \\
\text { weighted } \\
\text { biomass } \\
\text { abundance (\%) }\end{array}$ \\
\hline 0 & 43.3 & 0 & 0 \\
$1-5$ & 31.8 & 11.8 & 41.1 \\
$>5$ & 24.7 & 88.2 & 58.9 \\
$>10$ & 13.6 & 74.2 & 36.6 \\
$>25$ & 4.4 & 49.5 & 13.9 \\
$>50$ & 1.7 & 34.9 & 6.5 \\
\hline
\end{tabular}

The Tukey test results for $\Delta T$ and $\overline{C H L}$ (Fig. 7b,c) show very similar patterns of differences and similarities between all species, suggesting that all 3 of these habitat variables are similarly related to the habitat preferences of each individual species. This is expected, as the variables are related but occur over different time scales, with large changes in $\overline{C H L}$ (weekly) and $\Delta T$ (seasonally), whilst $\log _{10}\left(h / U^{3}\right)$ is a static variable. This suggests that $\log _{10}\left(h / U^{3}\right)$ and $\Delta T$ are 'long term' variables (annual and seasonal) that underpin the broad changes in distributional abundance, whilst levels of $\overline{C H L}$ are predictably linked to these physical parameters.

The biological and physical variables that were not significantly different across all species were $C H L_{\text {max }}$ $\mathrm{SD}(H)$ and Time (Table 3$)$. To investigate whether the lack of variation between the means for each species was due to a lack of variance in the variable across the study area, or if species were indeed targeting locations where that variable was of a similar value, we tested the means for each variable in the locations where the species were present versus the locations where they were absent. We found that for both $C H L_{\max }$ and $\operatorname{SD}(H)$, the mean values were highly significantly different $(\mathrm{t}=-6.14$ and $\mathrm{t}=-4.05$, respec- 
tively: $\mathrm{df}=968$ and $\mathrm{p}<0.001$ for both relationships). Both variables showed higher values in the locations with animals present rather than absent: 1.56 compared to $1.33 \mathrm{mg} \mathrm{m}^{-3}$ for $C H L_{\max }$ and 0.66 compared to $0.34 \mathrm{~m}^{2}$ for $\mathrm{SD}(H)$. The indication is that all animals were preferentially targeting areas with higher levels of $C H L_{\max }$ and more abrupt changes in bottom topography. There was no significant difference in Time (of day), between locations where animals were present and where they were absent; this implies that the lack of differences between means indicates similar variance across species, and that we did not have a bias in our sampling of Time (Table 3). In fact, all of the other 6 variables also showed no significant difference between locations with animal presence and locations with animal absence; what appears to be perfectly good habitat locations in terms of the important values of $\Delta T, \log _{10}\left(h / U^{3}\right)$ and $\overline{C H L}$ are not used for foraging when the preferred values for $C H L_{\max }$ and $S D H$ are not present. This also implies that those preferred parameter values are good indicators of fish prey being present.

\section{Multiple explanatory variables for species presence and absence}

Using GAMs, we explored how non-linear relations for combinations of multiple physical and biological variables might explain the presence/absence patterns that were observed for each species and for the combined species variable. All 7 species had viable presence/absence models. The most parsimonious models with the lowest AIC scores and only those variables with $\mathrm{p}<0.05$ are shown in Table 4. In general, the models did not explain much of the variation in the presence or absence of species. The guillemot model has the highest percentage of deviance explained $(40.1 \%)$, with grey seals $(25.7 \%)$ and harbour porpoise $(22.1 \%)$ the next highest. The model for the weighted biomass abundance of all animals explained $32.6 \%$ of deviance, with 7 out of 9 explanatory variables being significant.

The 4 significant variables that were most common across the species were $\log _{10}\left(h / U^{3}\right)$, Time, Seastate and $S D(H)$. Different species showed quite different non-linear relationships with $\log _{10}\left(h / U^{3}\right)$ as well as Time (Fig. 8). Guillemots and kittiwakes showed a minimum probability of presence at the same value of $\log _{10}$ $\left(h / U^{3}\right)\left(3.75 \mathrm{~m}^{-2} \mathrm{~s}^{3}\right)$, but probability of presence

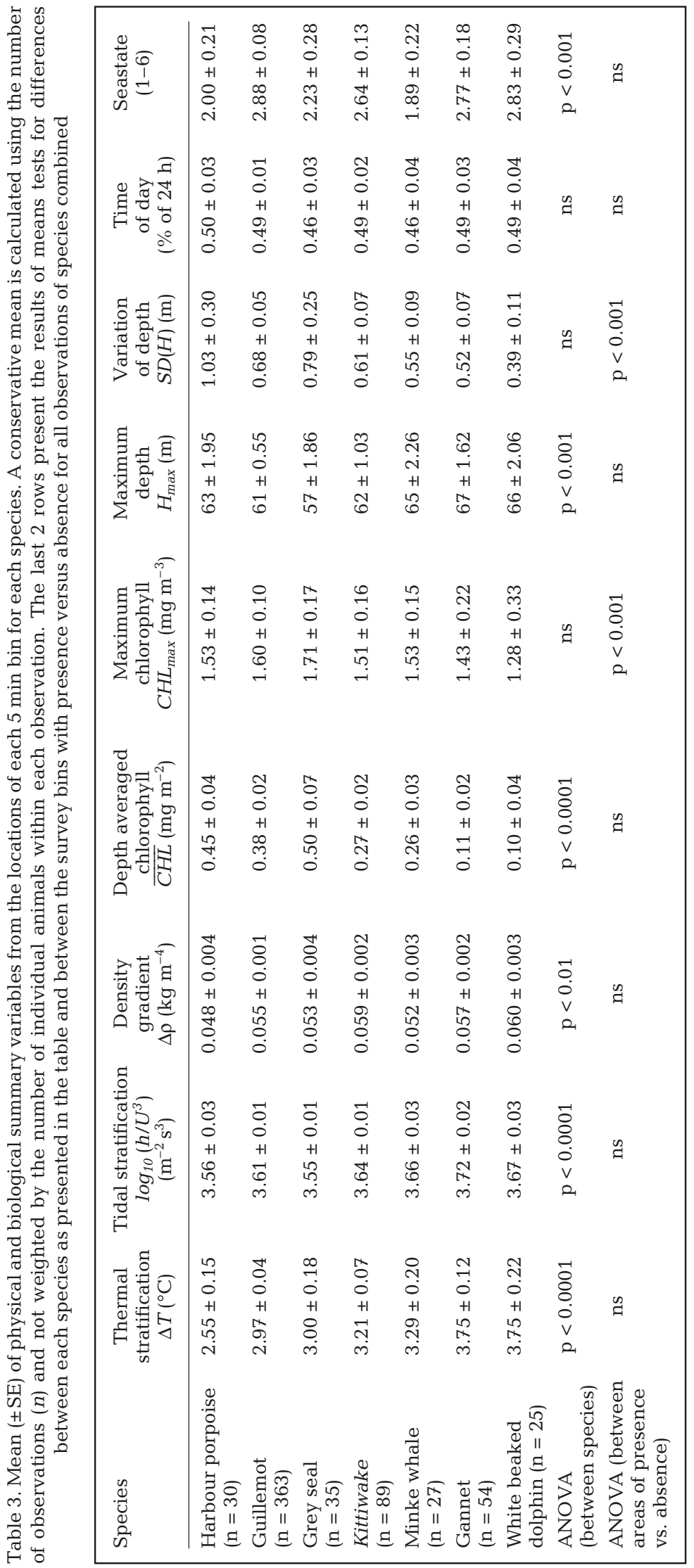



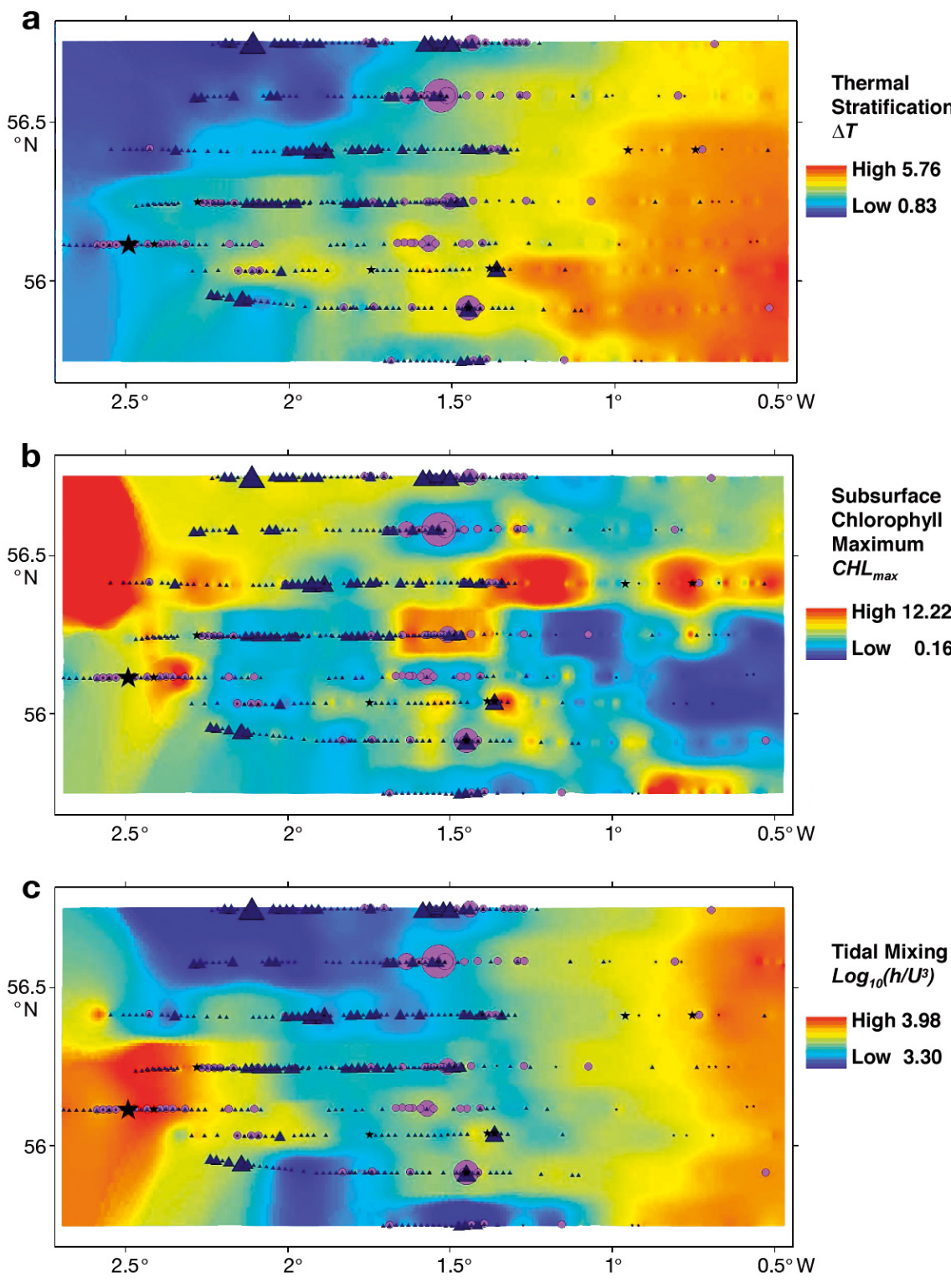

Guillemot

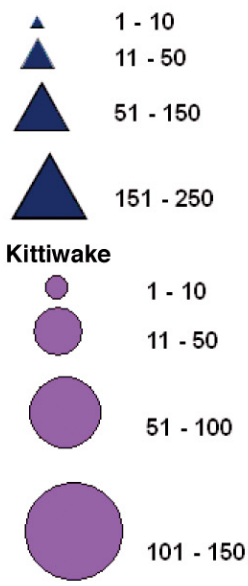

Gannet

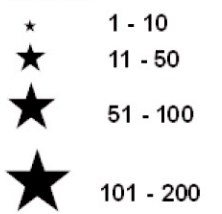

Fig. 4. Numbers of observed foraging seabirds on a background of 3 habitat characteristics of the water column. The values of the habitat variables are displayed using a linear interpolation of summary statistics of the 5 min bin observations. (a) Thermal stratification $(\Delta T)$ (b) sub-surface chlorophyll maximum $C H L_{\text {max }}$ (c) tidal mixing $\log _{10}\left(h / U^{3}\right)$. For clarity, the legend symbols are $2 \times$ the magnitude of the symbols within the Figs for gannets showed a positive linear increase with $\log _{10}\left(h / U^{3}\right)$ and grey seals showed an optimal level between 3.5 and $3.6 \mathrm{~m}^{-2} \mathrm{~s}^{3}$. Kittiwakes and gannets were similar for Time, with probability of presence maxima centred on 0.35 (08:40 h GMT) and minimums at $0.6(14: 40 \mathrm{~h})$, indicating a 6-hourly rise and fall of abundance; guillemot presence increased to an asymptote at $0.4(09: 30 \mathrm{~h})$ and harbour porpoise showed a clear optimum at 0.5 (midday: 12:00 h). Seastate and $S D(H)$ are not shown, as the shape of the relationship with Seastate was consistent and essentially negative linear, whilst $S D(H)$ was positive linear. The less commonly represented variables were $\Delta T$, $\overline{C H L}$ and $H_{\text {maxi }}$ however, all of these variables had similar relationships across species with viable models (Fig. 8).
Multiple explanatory variables for species abundance given presence

Using the second step in the GAM approach, we explored how the combination of multiple physical and biological variables might explain the abundance of species within those areas where they are present. Six of the 7 species had viable models. Again, only the most parsimonious models with the lowest AIC scores and those variables with $\mathrm{p}<0.05$ are shown (Table 5). The grey seal model has the highest percentage of deviance explained $(96.8 \%)$. The next best model was for gannets (83.8\%) and then kittiwakes $(54.2 \%)$. The model with all species combined was a poor model overall, explaining only $17.1 \%$ of deviance, suggesting that high abundances 

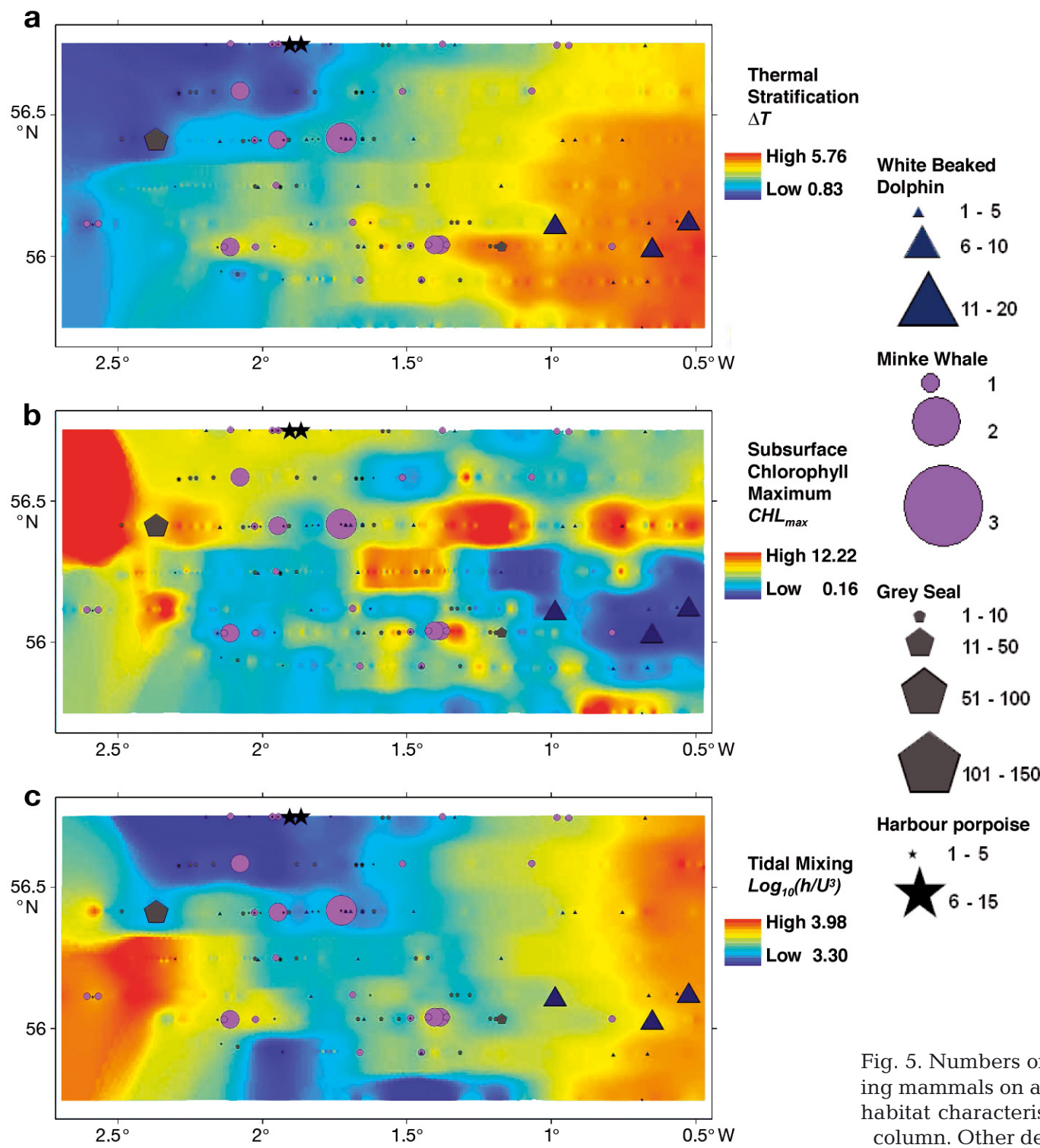

Harbour porpoise

Tidal Mixing

$\star \quad 1-5$

High 3.98

Low 3.30

White Beaked

Dolphin

- 1 - 5

‥ 6.10

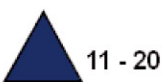

Minke Whale

Grey Seal

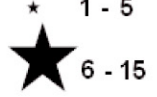

Fig. 5. Numbers of observed foraging mammals on a background of 3 habitat characteristics of the water column. Other details as in Fig. 4

of individual species are independent of the other species.

The variables that were most common across the species (present in 4 models) were again $\log _{10}\left(h / U^{3}\right)$ and, this time, $C H L_{\max }$. The same species have significant relationships with the explanatory variable, $\log _{10}\left(h / U^{3}\right)$, however the shape of the relationships are quite different from the presence/absence results (Fig. 9). Guillemots show a distinct drop off in abundance at a value of $3.75 \mathrm{~m}^{-2} \mathrm{~s}^{3}$, with rather stable levels at lower values suggesting a strong habitat preference for areas that are more mixed. Kittiwakes show a more distinct optimum between 3.5 and $3.6 \mathrm{~m}^{-2} \mathrm{~s}^{3}$. Gannets show a distinct increase in abundance from values of $3.8 \mathrm{~m}^{-2} \mathrm{~s}^{3}$ and upwards. Grey seals show a gradual increase in abundance with increasing values up to
$3.7 \mathrm{~m}^{-2} \mathrm{~s}^{3}$, but were not found at all above that value. Kittiwakes and white-beaked dolphins show the highest abundances at lower levels of $C H L_{\text {max }}$ whereas gannets show a clear increase up to an asymptotic value of $0.25\left(1.4 \mathrm{mg} \mathrm{m}^{-3}\right)$ and grey seals have a clear optimum at just over $0.3\left(2.0 \mathrm{mg} \mathrm{m}^{-3}\right)$.

$\overline{C H L}, \Delta T, H_{\max }$ and $S D(H)$ are all significant in 2 species models each (Fig. 9). Both guillemots and kittiwakes show optimum values for $\overline{C H L}$ of $0.20(0.92 \mathrm{mg}$ $\mathrm{m}^{-3}$ ) and $0.16\left(0.60 \mathrm{mg} \mathrm{m}^{-3}\right)$, respectively. Gannets show a clear optimum for $\Delta T$ at $4.0^{\circ} \mathrm{C}$ and kittiwakes show higher abundance at $\Delta T$ values lower than $4.0^{\circ} \mathrm{C}$. Grey seals obviously prefer shallower habitat, showing high increases in abundance in water less than $60 \mathrm{~m}$ deep; kittiwakes show optima between 50 and $60 \mathrm{~m}$. The kittiwake $S D(H)$ model shows increased abun- 

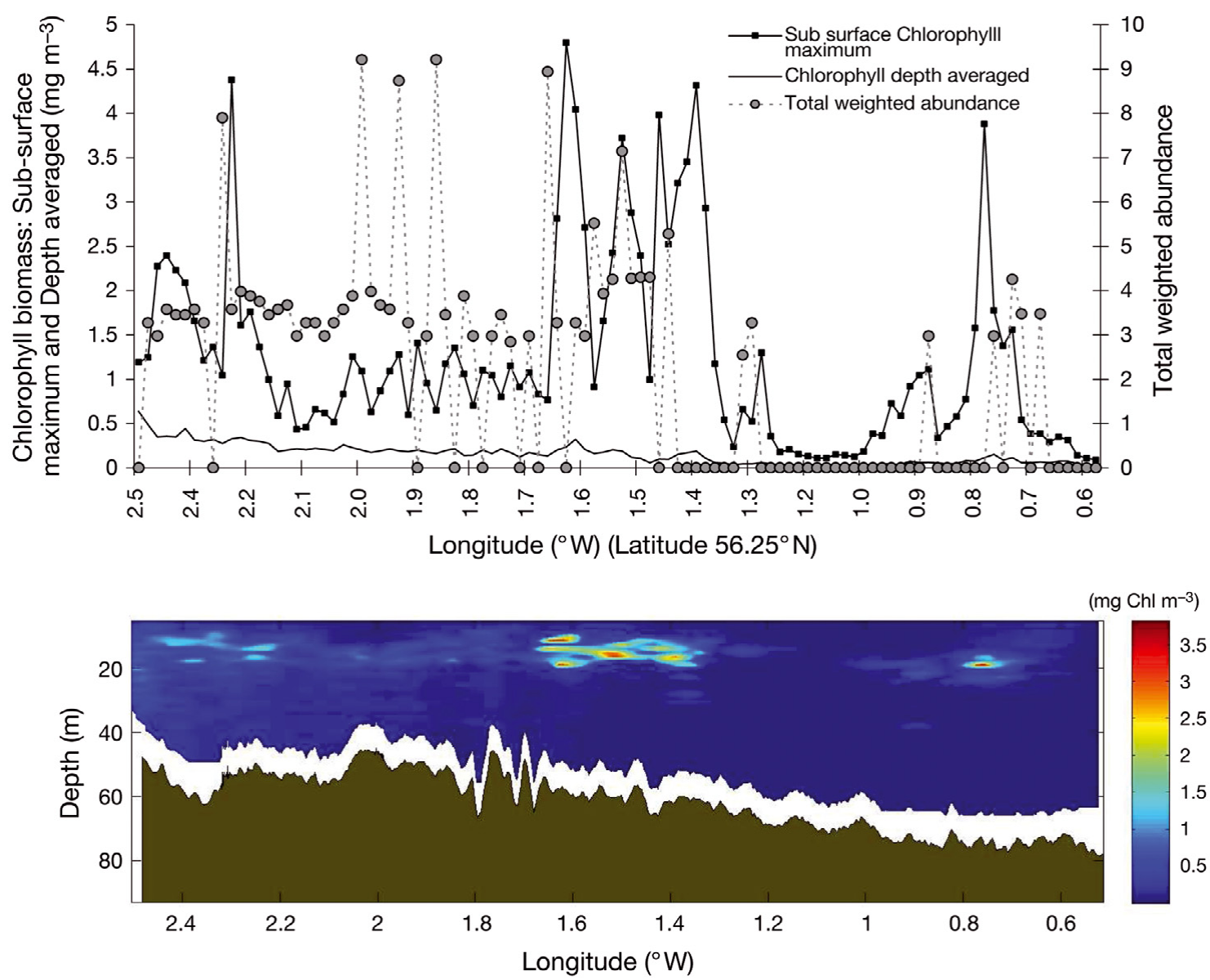

Fig. 6. All foraging animal species, represented as the total weighted biomass abundance as compared to both the sub-surface chlorophyll maximum, $C H L_{\max }$ and the depth averaged chlorophyll biomass, $\overline{C H L}$, in the upper panel. This is compared to the output of the continuous chlorophyll biomass recorded continuously by the undulating ScanFish for a representative transect of the survey

dance at values of 0.2 , which translates to $\pm 3.2 \mathrm{~m}$ $( \pm 2 \mathrm{SD}$ log transformed data), whereas the gannet model shows a linear increase in abundance with increasing variation in bottom depth.

\section{DISCUSSION}

\section{Spatially limited foraging locations}

In this study, we simultaneously analysed a combined range of actively foraging marine top-predators, with contrasting foraging behaviours, in relation to simultaneous and continuous oceanographic data in a shallow sea region $(<200 \mathrm{~m})$. The implications of this study are that the foraging locations for a range of species are extremely limited in space. We found $50 \%$ of all animals foraging in very patchy distributions $(<2 \mathrm{~km})$, but with high foraging abundances ( $>25$ individuals, whereas the mean was only 6 individuals per 5 min survey bin) concentrated in only $4.4 \%$ of the area surveyed (Table 2, Figs. 4 \& 5). These high-abundance locations were found to be species-specific, as the weighted biomass abundance value for these areas was only $14 \%$ of the total; although there were high numbers of animals present within any one $1.24 \mathrm{~km}$ observational $5 \mathrm{~min}$ bin unit, they were composed mainly of a single species.

We have also been able to identify both the important differences and similarities between species over a range of foraging location habitat values, as the $\sim 10000 \mathrm{~km}^{2}$ study area contained a wide range of the stratification characteristics typical of shallow seas. Due to the time of year of the survey, the entire area was stratified (Fig. 1). The locations of high integrated chlorophyll biomass and locations of $C H L_{\max }$ were quite dissimilar, with locations of high $C H L_{\max }$ being extremely patchy at scales of approximately 2 to $10 \mathrm{~km}$ (Fig. 2). Interestingly, areas of high $C H L_{\max }$ were only found in locations with values of $\log _{10}\left(h / U^{3}\right)>3.55 \mathrm{~m}^{-2}$ $\mathrm{s}^{3}$, suggesting that these types of patches will only be found in more strongly stratified water columns, 
a) Tidal mixing variable $\log _{10}\left(h / U^{3}\right)$

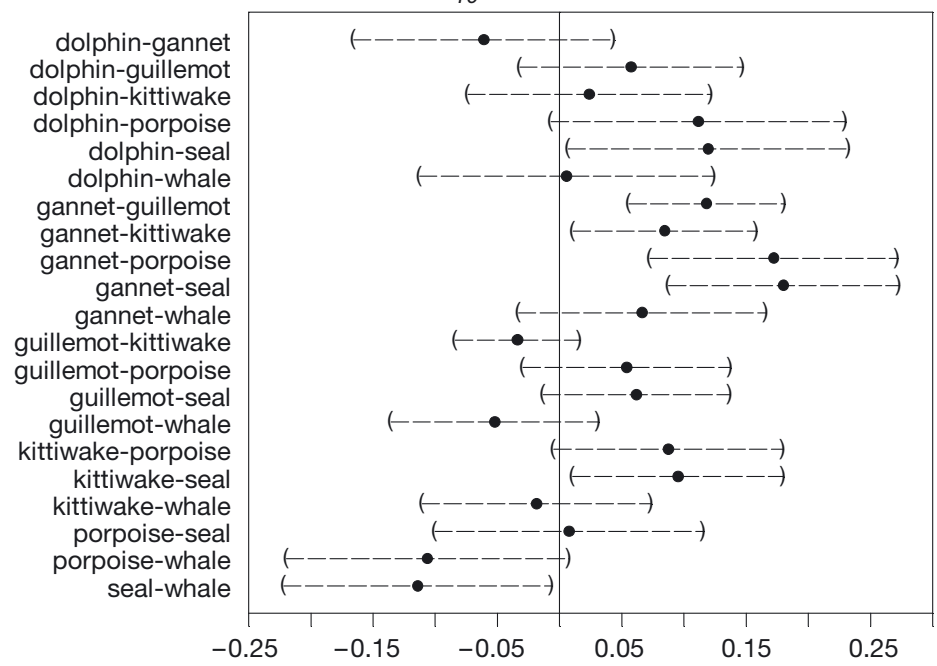

b) Thermal stratification variable $\Delta T$

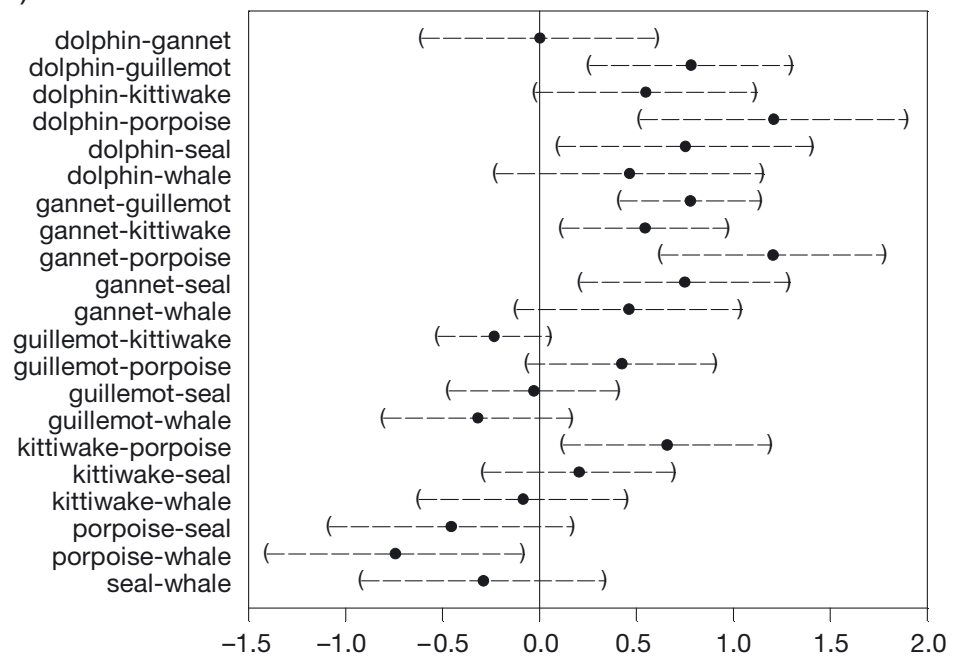

c) Depth averaged chlorophyll variable $\overline{\mathrm{CHL}}$

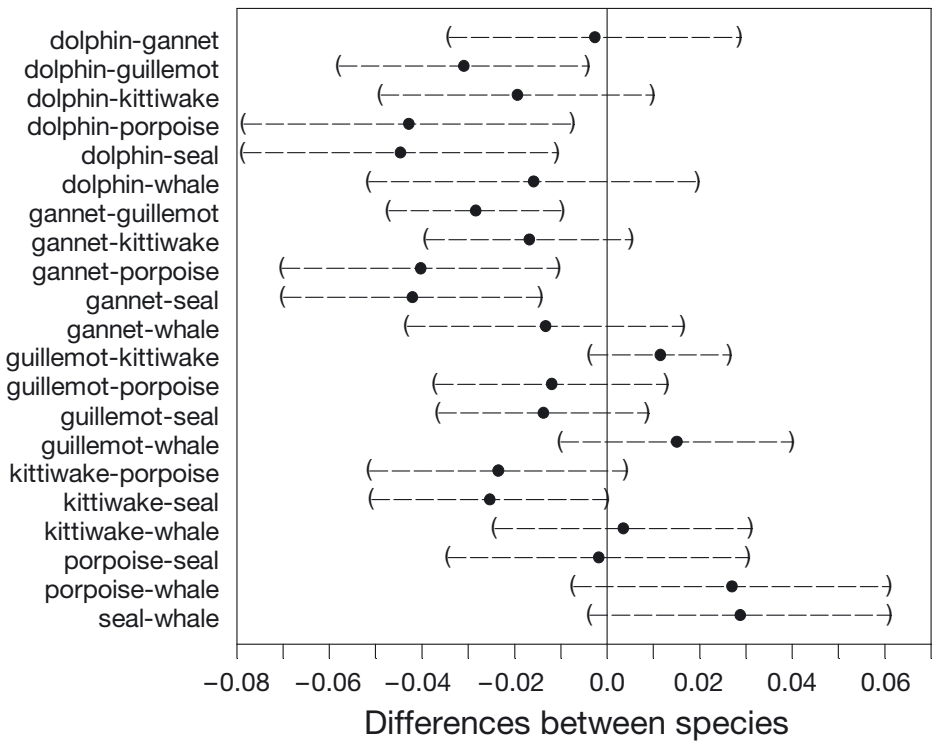

whereas areas of highest $\overline{C H L}$ are only within regions where $\log _{10}\left(h / U^{3}\right)$ is $<3.55 \mathrm{~m}^{-2} \mathrm{~s}^{3}$, suggesting that the value of $3.55 \mathrm{~m}^{-2} \mathrm{~s}^{3}$ has some biological significance. Also, there is a definite lack of both $C H L_{\max }$ patches and top predators between values of 3.70 and $3.80 \mathrm{~m}^{-2} \mathrm{~s}^{3}$ even though there are high levels of both with values between 3.55 and $3.70 \mathrm{~m}^{-2} \mathrm{~s}^{3}$ and also $>3.80 \mathrm{~m}^{-2} \mathrm{~s}^{3}$, suggesting that this level of stratification is not conducive to the creation of foraging areas. Alternatively, it could just be coincidence within this study region.

\section{Foraging habitats: differences}

Static value: tidal stratification as an indicator of foraging location

A main conclusion of this study is that that the top predators studied here are more likely to forage in different locations, defined to some extent by the level of stratification. $\log _{10}\left(h / U^{3}\right)$ is an inverse measure of tidal mixing normalised by the water depth, and was shown to be significantly different between species (Table 3, Figs. 4, 5 \& 6) as well as being the most consistent variable in most presence/absence and abundance models (Tables 4 \& 5, Figs. $8 \& 9$ ). The results suggest that gannets and white-beaked dolphins prefer to forage in significantly more stratified regions than other species. Kittiwakes and minke whales seem to prefer moderately stratified areas but the whales generally used different habitat from other mammals. Guillemots, grey seals and harbour porpoises preferred areas that were much less stratified than the other species.

Tidal stratification, $\log _{10}\left(h / U^{3}\right)$, is a very useful static variable as not only does it combine depth and tidal current values into one variable, but also both types of data are readily available for most shallow sea regions. Testing the foraging location preference, defined by $\log _{10}\left(h / U^{3}\right)$, for different species can readily be accomplished through the

Fig. 7. Simultaneous pair-wise mean difference and $95 \%$ confidence limits (Tukey method) between (a) $\log _{10}\left(h / U^{3}\right)$, (b) $\Delta T$ and (c) $\overline{C H L}$ values for tidal mixing for each combination of foraging species. The dot represents the difference between the means of each 2 pairs of species, with positive differences indicating that the species on the right (on the $y$-axis) forages in water masses with higher variable values than the species on the left (vice versa for negative values). Dotted lines and brackets represent the $95 \%$ confidence limits; for those species which are in significantly different water mass types, the $95 \%$ confidence limits do not intercept the zero axes 
use of long-term survey data held at many national agencies. The level of stratification a species prefers may also help to enlighten studies on mechanistic links between any observed changes in foraging behaviours, distributions, climate (seasonal stratification and wind mixing effects) and annual survival.

\section{Seasonal variables: thermal stratification and mean chlorophyll biomass}

Different species also used foraging habitats with significant differences in the seasonal variables $\Delta T$ and $\overline{C H L}$. The absolute values for $\Delta T$ and $\overline{C H L}$ will be affected by annual differences in the strength and timing of winds, heat input and nutrient concentrations, making it more difficult to obtain the spatial values for these variables without field sampling. However, both variables showed approximately the same pattern between species as found for $\log _{10}\left(h / U^{3}\right)$ in the Tukey analysis (Fig. 6). This is logical as $\log _{10}\left(h / U^{3}\right)$ defines the area's tendency to stratify or vertically mix, which influences $\overline{C H L}$ values. Importantly though, in the additive models where these variables were significant, whether in the presence/ absence or the abundance models, the relationships were generally one with an optimum value (Figs. 8 \& 9). Together these results suggest that, overall, $\log _{10}\left(h / U^{3}\right)$ underpins the broad differences in species foraging distributions, but that seasonal differences in $\Delta T$ and $\overline{C H L}$ drive the smaller scale factors in foraging locations.

\section{Daily variables: Seastate and Time}

The other habitat variables that played significant roles in explaining the variation in the presence/absence of animals were Seastate and Time. However, neither variable had much of a role in accounting for abundance. Both of these are variables that change on an hourly scale, with Seastate consistently showing a negative linear relation with presence, as expected (Table 4 \& 5). Although Time showed no significant linear differences between species (Table 3), there are differences in the non-linear shape of relationships (additive models, Fig. 8) for the presence of 4 species. The probability of presence for all the seabird species builds from the early morning to a maximum at 08:40 $\mathrm{h}$ (GMT). This suggests that the increase in birds over time is most likely due to breeders that have flown out from a nest site in the

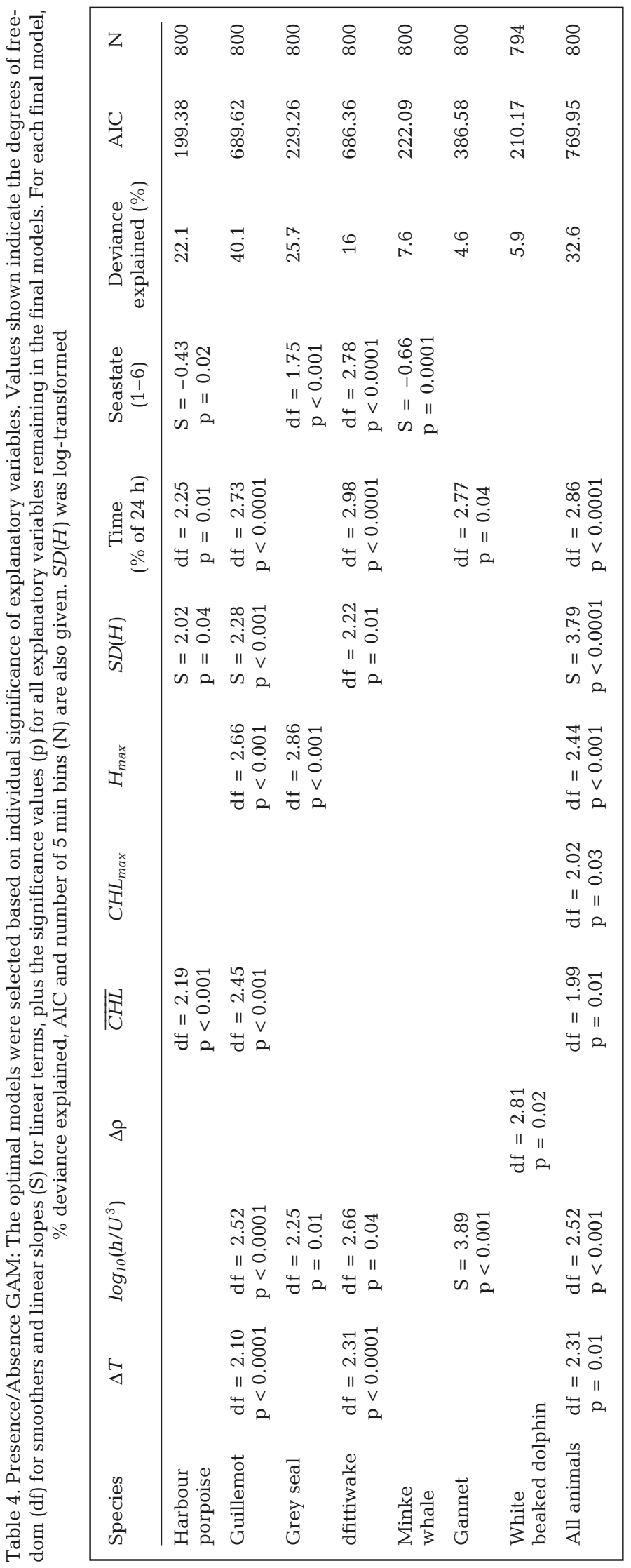



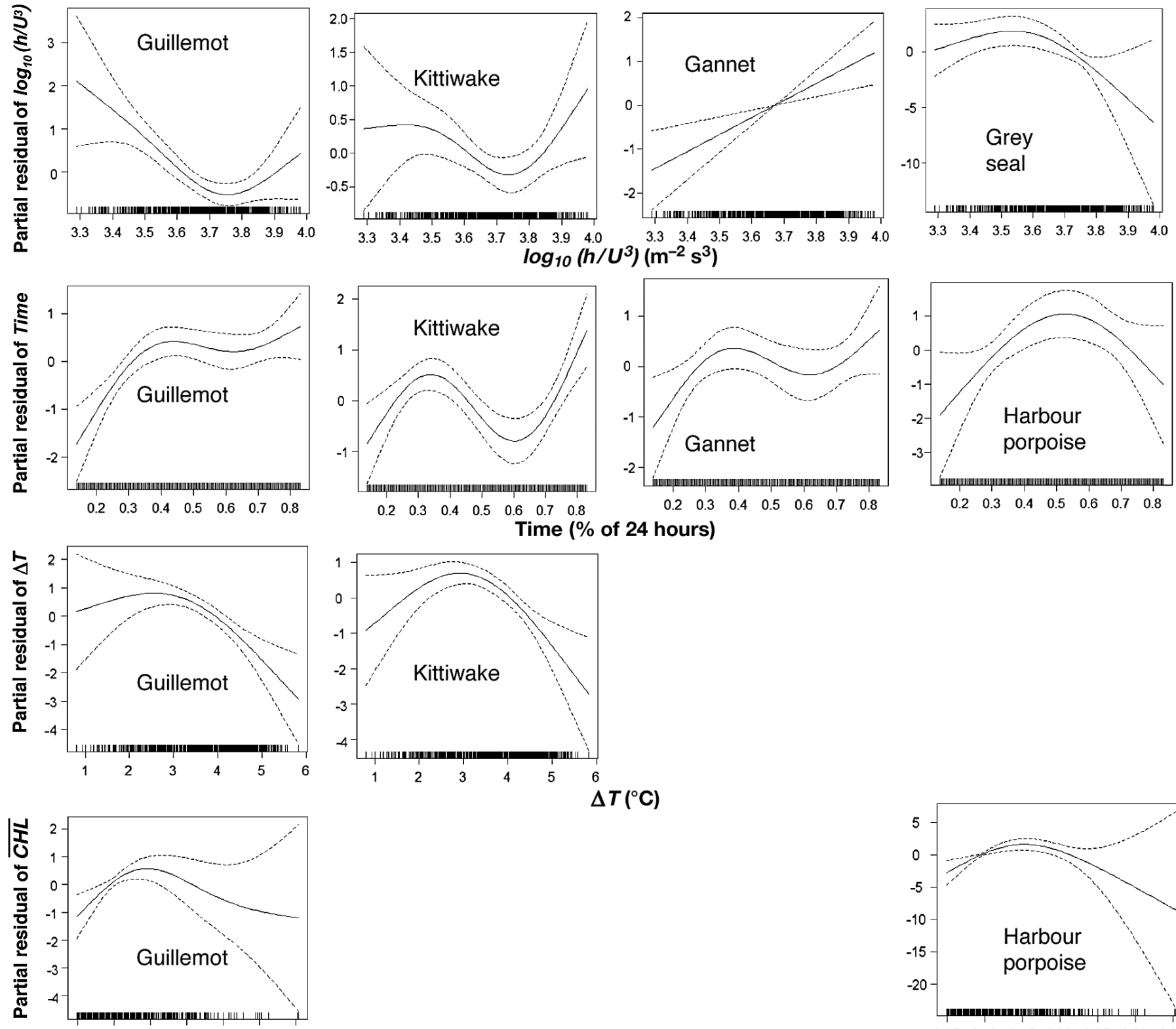

$\Delta T\left({ }^{\circ} \mathbf{C}\right)$

$\begin{array}{lllllll}0.05 & 0.10 & 0.15 & 0.20 & 0.25 & 0.30 & 0.35\end{array}$

\section{$\overline{C H L}\left(\mathrm{mg} \mathrm{m}^{-3}\right)$}
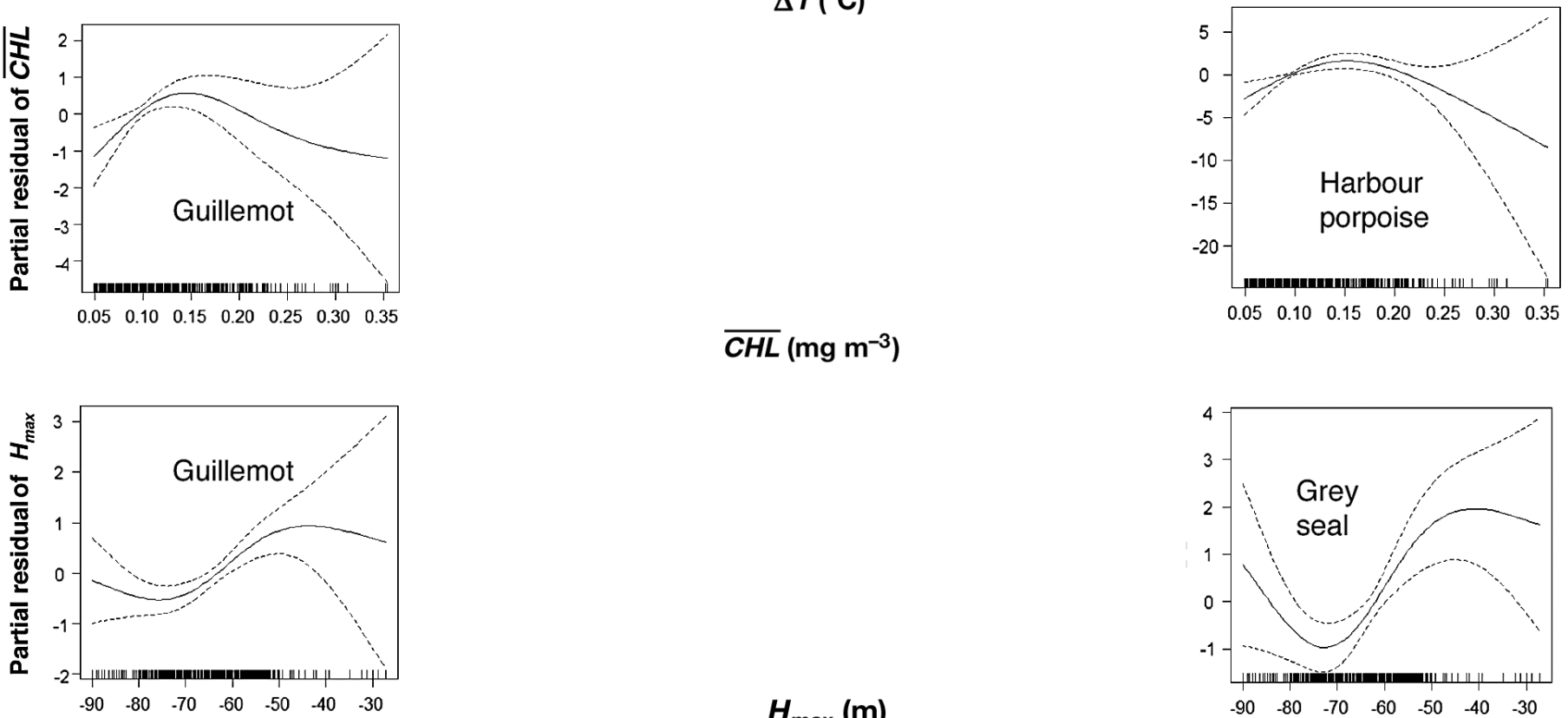

$\boldsymbol{H}_{\max }(\mathrm{m})$

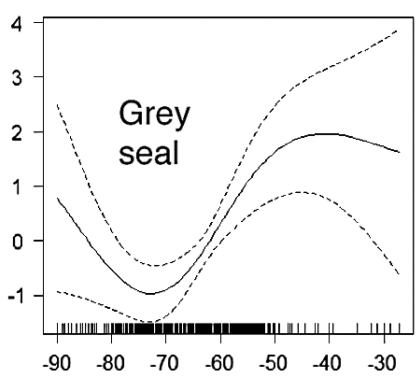

Fig. 8. GAM relationships (smoothing spline of the partial residual and $95 \%$ confidence intervals) for the presence/absence of 5 significant explanatory variables, $\log _{10}\left(h / U^{3}\right)$, Time, $\Delta T, \overline{C H L}, H_{\max }$. In each row, the same partial residual for an explanatory variable is presented as the $y$-axis. The values on the $y$-axis indicated either an increased probability of presence $(>0)$ or absence $(<0)$. For each row, the $x$-axis has the same explanatory variable. Each column contains the same marine top-predator species where possible. Note that $S e a s t a t e$ and $S D(H)$ are also significant explanatory variables, but they are not shown as they are linear relationships 
early morning. However, for kittiwakes and gannets, there is also a definite $6 \mathrm{~h}$ pattern to the probability of presence, suggesting that their foraging behaviour is linked to changes in tidal currents. Kittiwake foraging was indeed found to be more frequent at certain tidal speeds in this study area (C. E. Embling et al. unpubl.).

These results imply that even though we occasionally witnessed spectacular feeding frenzies with multiple foraging species, the usual foraging behaviour for most species is to specialise in separate locations from other species. Some of this degree of separation between species may be directly linked to negative interaction, such as aggressive behaviour between dolphins and harbour porpoises (Ross \& Wilson 1996). Indeed, our motivation for creating a response variable that was a weighted index of total biomass abundance of all predators was to explore whether combining species increased the predictability of locations of presence or high abundance. The fact that combining species as if they were a 'super predator' did not do well at explaining much of the variation in these factors lends more weight to the suggestion that predators forage separately most of the time. This strongly suggests that the range of top predators studied are either more efficient at catching the same prey in slightly different habitats, which can be defined by $\log _{10}\left(h / U^{3}\right)$, or that they are targeting different prey fish species which occur in these different habitats. Indeed, studies of minke whales and harbour porpoise foraging at fine spatial scales have also found that different species may use the same oceanographic feature (e.g. an island wake), but with different species using different aspects of that feature (Johnston et al. 2005a,b). The times of overlap between multiple species foraging events are spectacular to view, and indeed many a dramatic nature documentary has been produced that focuses just on these events. However, our data strongly suggest that these events are rare in this geographic region and that most species will have separate foraging habitats most of the time, if only a few $\mathrm{km}$ away from each other.

\section{Foraging habitats: similarities}

Similarities across species: $C H L_{\max }$ and $S D(H)$

Although the 7 species studied forage using different methods and in different locations, they appear to target 2 common physical and

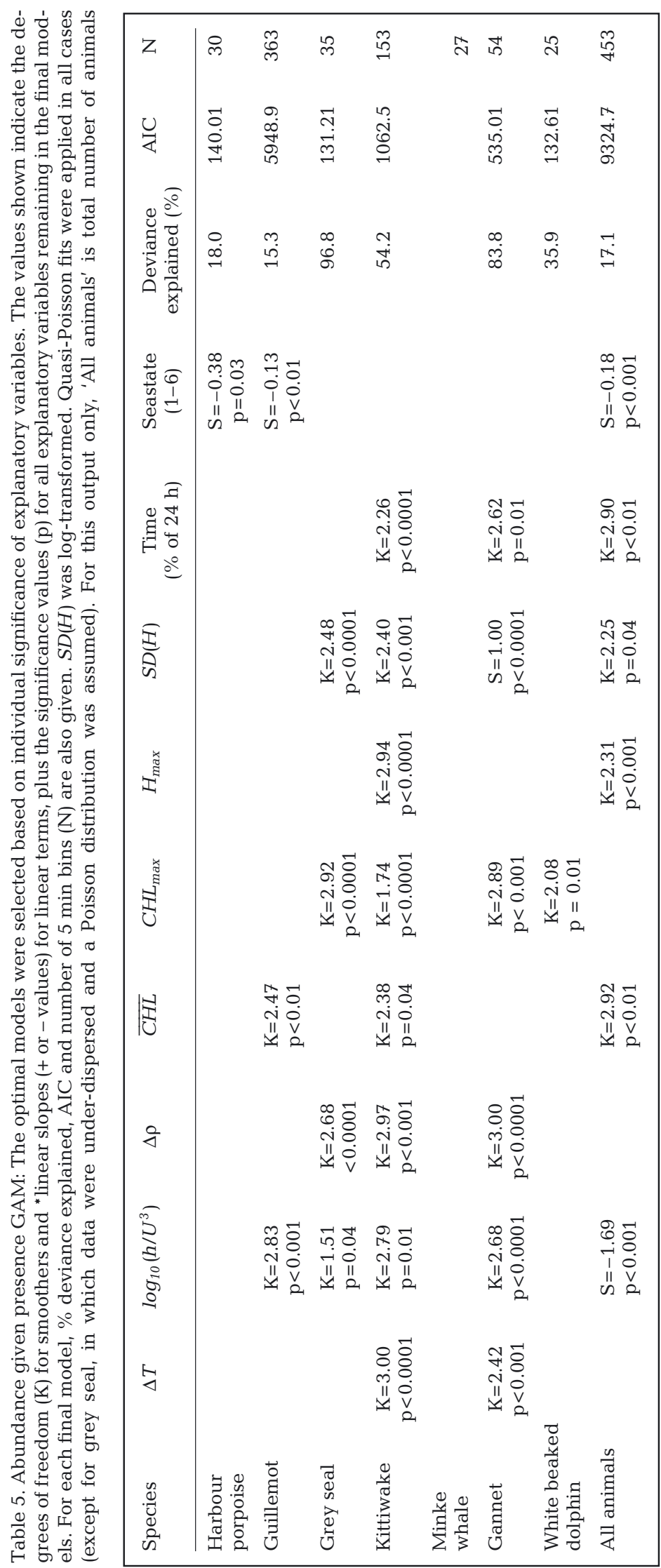



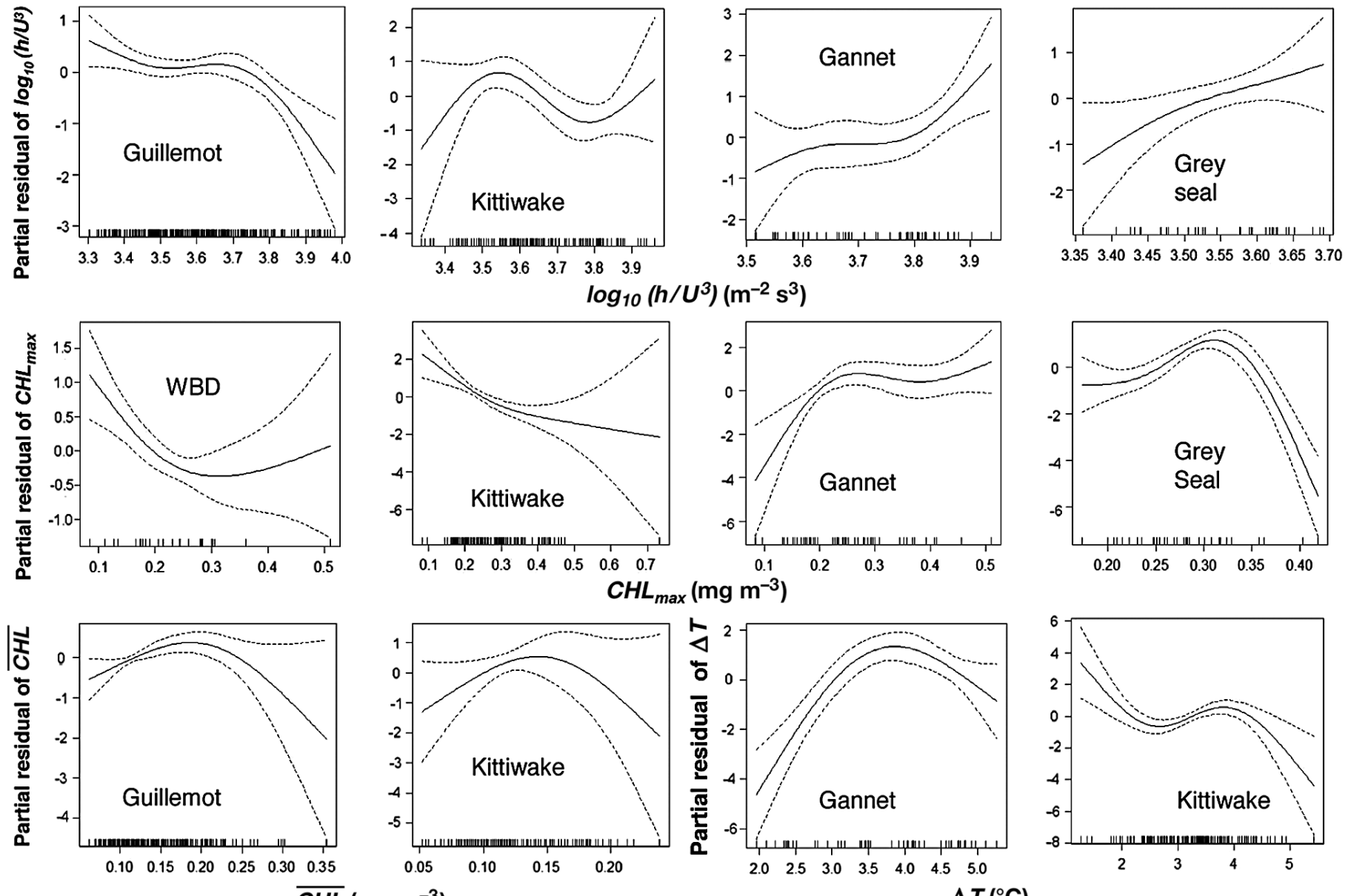

$\overline{C H L}\left(\mathrm{mg} \mathrm{m}^{-3}\right)$

$\Delta T\left({ }^{\circ} \mathrm{C}\right)$

몰
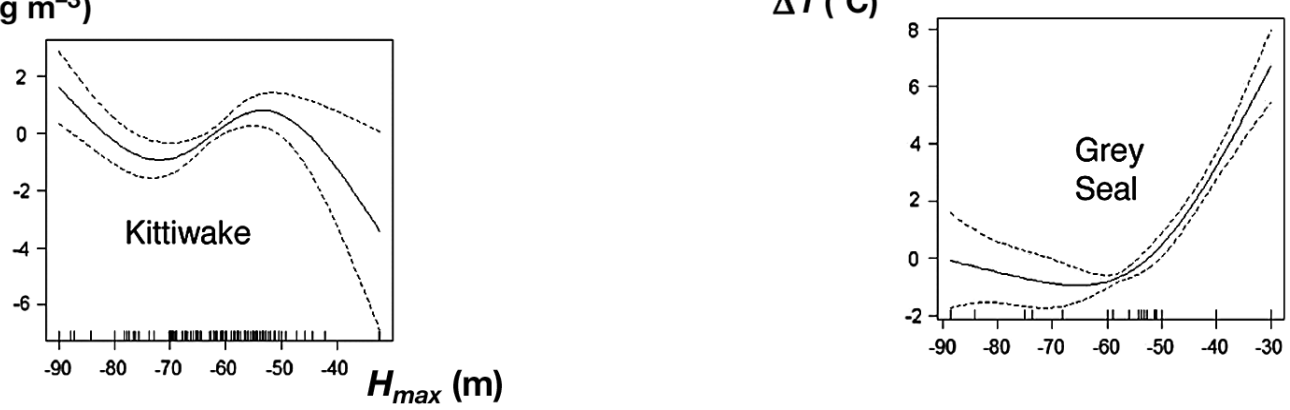

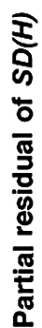
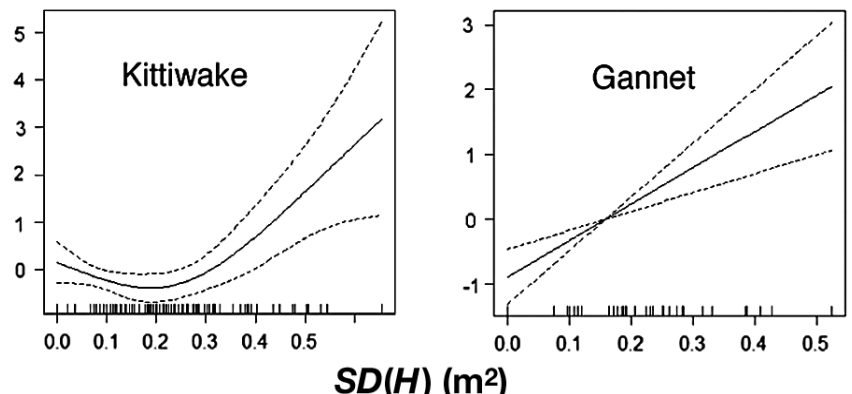

Fig. 9. GAM relationships (smoothing spline of the partial residual and $95 \%$ confidence intervals) for abundance of all the significant explanatory variables, $\log _{10}\left(h / U^{3}\right), C H L_{\max }, \overline{C H L}, H_{\max } S D(H)$. In each row, the same partial residual for an explanatory variable is presented as the $y$-axis (except row 3, where 2 explanatory variables are on the same row). The values on the $y$-axis indicated either an increased probability of an increase in abundance $(>0)$ or an increased probability of a decrease in abundance $(<0)$. For each row, the $x$-axis has the same explanatory variable (except row 3 , where 2 explanatory variables are on the same row). Each column contains the same top predator species where possible 
biological oceanographic features: higher levels of subsurface chlorophyll biomass $\left(C H L_{\max }\right)$ and higher variation in bottom depth $(S D(H))$. These were the only single variables that had significant differences between the regions of species presence and absence and yet showed no difference in mean values between all the species (Table 3). This suggests that all 7 species are targeting similar values for these variables and that these are therefore highly important general factors in identifying foraging locations across species.

\section{Subsurface chlorophyll maximum $\left(\mathrm{CH}_{\max }\right)$}

$C H L_{\max }$ is a significant variable in 4 of the abundance models but shows a different shaped relationship for those species (kittiwake, gannet, white-beaked dolphins and grey seal: Fig. 9). We hypothesise that top predator species are using these areas of $C H L_{\max }$ for foraging as they may be predictable in both space and time. Their patchiness also suggests the possibility that they are limited point-source locations of primary production in the stratified sections of shallow seas.

One limitation of this study is that it is a 'snapshot' in time, and we suggest that caution is exercised in interpreting the results. However, information from independent multiple-year studies mapping grey seal foraging locations using satellite tags (Matthiopoulos et al. 2004) reveal that seals are consistently found within the same areas that show high sub-surface chlorophyll in our data (Fig. 2b). Also, seasonal effects of chlorophyll production based on site specific mooring studies within this study area (Scott et al. 2006, Sharples et al. 2006) have been used in longer-term analysis. A fisheries study, focused on a subsection of this study area since 1997, has shown that incorporating seasonal chlorophyll production does explain sampling variance in fish abundance (Greenstreet et al. 2006). We therefore suggest that the predictability of these locations may allow highly mobile marine predators to remember and re-visit these areas, and that the persistent aggregations of phytoplankton will attract a range of zooplankton and fish species (similar to frontal regions: Durazo et al. 1998, Sims \& Quayle 1998, Russell et al. 1999, Lough \& Manning 2001). Prey species will move in and out of these areas depending on their species-specific foraging strategies, predator avoidance behaviours and migration patterns. However, any changes to primary production (i.e. phenology, abundance, species composition), and hence to trophic energy transfer, will be quickly reflected by changes in mobile predator foraging behaviour, distribution, and annual reproductive success. For instance, the timing of the spring bloom in this region significantly affects the reproductive success of kittiwakes (Scott et al. 2006, Sharples et al. 2006).
Variability in depth

In general, the shape of the relationship between $S D(H)$ and presence/absence or abundance is one of positive linear increase, with slopes ranging from 1 to 2.28 (Tables 4 \& 5); this confirms that increasing variation in depth, if only by meters in a shallow sea, leads to the probability of increases in predator presence. Therefore, the combination of these results suggests that all 7 species forage within, or very near, locations with higher levels of sub-surface chlorophyll and that more animals were found where there was higher variation in depth. However, there was no significant relationship between just $C H L_{\max }$ and $S D(H)$, suggesting that additional factors such as stratification must also have the necessary values within those locations before they provide an environment for high concentrations of top predators.

\section{What defines critical foraging habitat?}

Firstly, the findings of this study point to a need to understand the mechanism(s) for the creation of patchy locations of sub-surface chlorophyll maximum $\left(\mathrm{CHL}_{\max }\right)$ before trying to predict the exact locations of these critical areas at the spatial scale at which they occur. We surveyed some of these hotspots in circuits repeated every $2 \mathrm{~h}$ over whole tidal cycles and showed that tidal speed both affects the behaviour of the main prey fish species, sandeel Ammodytes marinus, via a change in schooling behaviour, and produces increases in the foraging activity of surface feeding birds (C. E. Embling et al. unpubl.).

Secondly, we hypothesise that increased variation in bottom depth $(S D(H))$ leads to an increased probability of presence and abundance for most of our study species. This indicates that slope-generated mixing may be playing an important role in creating these critical areas, as this factor may be responsible for the generation of internal waves. Briefly, the formation of internal waves, with typical wavelengths in the range of 1 to $2 \mathrm{~km}$ and amplitudes of 10 to $20 \mathrm{~m}$, are created by flow over non-uniform topography during high and falling tidal current speeds in areas where the water column is stratified (Moum \& Nash 2000, Sharples 2008). The increase in vertical mixing due to internal waves may increase primary production and may also assist in aggregating smaller prey items, making foraging more likely in these areas. To date there have been only a few studies which look at trophic interactions at these fine spatial and temporal scales (Moore \& Lien 2007, Bertrand et al. 2008, Stevik et al. 2008) and they have all found internal waves to be a possible mechanism for enhancing trophic coupling. 


\section{CONCLUSIONS}

Most fish species are both predators and prey, and as such their behaviour will switch between evasion of predators and their own feeding. In contrast, apex predators such as seabirds and marine mammals are mainly concerned with feeding, such that their foraging times and locations will represent a foraging strategy focused at productive locations and constrained only by breeding behaviour. Encouragingly, we found that the fine scales characteristic of this study $(\sim 2$ to $10 \mathrm{~km}$ ) were the same habitat variables (topography, primary production and water column mixing characteristics) that are found to be important in determining top predator distributions at much larger spatial $(\sim 100 \mathrm{~km})$ and temporal scales (Genin 2004, Yen et al. 2004, Bakun 2006, Ballance et al. 2006), and may help to explain why others have found an absence of scale dependence for dolphin habitat (Redfern et al. 2008). However, this study uniquely focused this question within a representative $10000 \mathrm{~km}^{2}$ region of shallow sea, where there are changes of only tens of metres in depth and no frontal areas (as defined by Simpson \& Hunter 1974 or Sharples 2008). Our conclusion is that, in shallow seas, $\log _{10}\left(h / U^{3}\right)$ is a very important predictive habitat variable and that values of $\log _{10}\left(h / U^{3}\right)$ beyond frontal areas are also biologically important.

Understanding exactly why subsurface chlorophyll patches are important to predators is particularly challenging but necessary to predict where these potentially transient but critical habitats will occur. As these patches appear to be associated with topographically driven internal waves, there are 2 alternative hypotheses which could explain the localised concentration of predators in such areas: (1) they result from complex trophic interactions via 'bottom-up forcing', with more prey available due to higher primary productivity where internal waves have caused vertical mixing of nutrients; or (2) they result from just topographical forcing, with prey in those areas simply easier to catch as the internal waves bring them closer to the surface and/or aggregate them. Testing these alternate hypotheses and understanding exactly where, when and why larger predators move into, and actively forage within, specific locations will enhance the decision making process on a wide range of marine conservation issues.

These extremely patchy areas represent a newly identified class of spatially important location, with subsurface chlorophyll characteristics that are not readily identifiable from surface characteristics (Weston et al. 2005), yet they may play a critical role in trophic coupling within regions of stratified water in shallow seas and need to be understood in detail. This level of understanding is needed for the spatial planning of the marine environment, such as decisions on the design and locations of marine protected areas (MPA), spatially explicit fishing management and providing confidence that placement of offshore renewable energy devices will not overlap or interfere with these areas of critical marine habitat.

Acknowledgements. Funding for original fieldwork was via EU Q5RS 2000-30864, IMPRESS (Interactions between the Marine Environment, Predators and prey: implications for Sustainable Sandeel fisheries). Funding for extended work was provided by NERC Sustainable Marine Bioresources programme NE/F001983/1; G.J.P. was funded under the EU Marie Curie programme (MEXC-CT-2006-042337). Special thanks to the crew of the 'Pelagia', especially Martin Laan and Santiago Gonsalez. Bird/sea mammal observers: Suzan van Lieshout, Luc Meeuwisse, Phillip Schwemmer and Nicole Sonntag. Volunteers for oceanography: Jackie Smith, Damion Nixon and Dr. Patrick Holligan (University of Southampton) for the analysis of the chlorophyll samples. Very special thanks for great efforts from FRS Marine Lab, Aberdeen: John Dunn and Eric Armstrong. We thank Dr. Lisa Ballance and 2 anonymous reviewers whose suggestions enhanced the work. We also acknowledge C. D. Macleod for extracting and configuring the BGS data and Proudman Oceanographic Laboratories for the use of POLPRED.

\section{LITERATURE CITED}

Ashmole NP (1971) Sea bird ecology and the marine environment. In: Farner DS, King JR (eds) Avian Biology, Vol 1. Academic Press, New York, NY p 224-286

$>$ Bakun A (2006) Fronts and eddies as key structures in the habitats of marine fish larvae: opportunity, adaptive response and competitive advantage. Sci Mar 70:105-122

- Ballance LT, Pitman RL, Fiedler PC (2006) Oceanographic influences on seabirds and cetaceans of the eastern tropical Pacific. A review. Prog Oceanogr 69:360-390

Bertrand A, Gerlotto F, Bertrand S, Gutiérrez M, and others (2008) Schooling behaviour and environmental forcing in relation to anchoveta distribution: An analysis across multiple spatial scales. Prog Oceanogr 79:264-277

Bost CA, Cotté C, Bailleul F, Cherel Y and others (2009) The importance of oceanographic fronts to marine birds and mammals of the southern oceans. J Mar Syst 78:363-376

Buckland ST, Anderson DR, Burnham KP, Laake JL, Borchers DL, Thomas L (2001) Introduction to distance sampling: Estimating abundance of biological populations. Oxford University Press, Oxford

Burger AE (2003) Effects of the Juan de Fuca Eddy and upwelling on densities and distributions of seabirds off southwest Vancouver Island, British Columbia. Mar Ornithol 31:113-122

Camphuysen CJ, Garthe S (2004) Recording foraging seabirds at sea: standardised recording and coding of foraging behaviour and multi-species foraging associations. Atlantic Seabirds 6:1-32

Camphuysen CJ, Fox AD, Leopold MF, Petersen IK (2004) Towards standardised seabirds at sea census techniques in connection with environmental impact assessments for offshore wind farms in the UK. Report commissioned by COWRIE for the Crown Estate, London. Royal Netherlands Institute for Sea Research, Texel

Cotté C, Simard Y (2005) Formation of dense krill patches 
under tidal forcing at whale feeding hot spots in the St. Lawrence Estuary. Mar Ecol Prog Ser 288:199-210

Cushing DH (1975) Marine ecology and fisheries. Cambridge University, Cambridge

Decker MB, Hunt GL Jr (1996) Foraging by murres (Uria spp.) at tidal fronts surrounding the Pribilof Islands, Alaska, USA. Mar Ecol Prog Ser 139:1-10

> Durazo R, Harrison NM, Hill AE (1998) Seabird observations at a tidal mixing front in the Irish sea. Estuar Coast Shelf Sci 47:153-164

Franks PJS, Chen C (1996) Plankton production in tidal fronts: A model of Georges Bank in summer. J Mar Res 54: 631-651

Genin A (2004) Bio-physical coupling in the formation of zooplankton and fish aggregations over abrupt topographies. J Mar Syst 50:3-20

Greenstreet SPR, Armstrong E, Mosegaard H, Jensen H and others (2006) Variation in the abundance of sandeels Ammodytes marinus off southeast Scotland: an evaluation of area-closure fisheries management and stock abundance assessment methods. ICES J Mar Sci 63:1530-1550

Irons DB (1998) Foraging area fidelity of individual seabirds in relation to tidal cycles and flock feeding. Ecol 79:647-655

Johnston DW, Westgate AJ, Read AJ (2005a) Effects of finescale oceanographic features on the distribution and movements of harbour porpoises Phocoena phocoena in the Bay of Fundy. Mar Ecol Prog Ser 295:279-293

> Johnston DW, Thorne LH, Read AJ (2005b) Fin whales Balaenoptera physalus and minke whales Balaenoptera acutorostrata exploit a tidally driven island wake ecosystem in the Bay of Fundy. Mar Ecol Prog Ser 305:287-295

Ladd C, Jahncke J, Hunt GL Jr, Coyle KO, Stabeno PJ (2005) Hydrographic features and seabird foraging in Aleutian Passes. Fish Oceanogr 14(Suppl. 1):178-195

Lough RG, Manning JP (2001) Tidal-front entrainment and retention of fish larvae on the southern flank of Georges Bank. Deep-Sea Res II 48:631-644

Matthiopoulos J, McConnell B, Duck C, Fedak M (2004) Using satellite telemetry and aerial counts to estimate space use by grey seals around the British Isles. J Appl Ecol 41:476-491

Mendes S, Turrell W, Lütkebohle T, Thompson P (2002) Influence of the tidal cycle and a tidal intrusion front on the spatio-temporal distribution of coastal bottlenose dolphins. Mar Ecol Prog Ser 239:221-229

> Moore SE, Lien RC (2007) Pilot whales follow internal solitary waves in the south China Sea. Mar Mamm Sci 23:193-196

> Moum JN, Nash JD (2000) Topographically induced drag and mixing at a small bank on the continental shelf. J Phys Oceanogr 30:2049-2054

Pingree RD, Griffiths DK (1978) Tidal fronts on shelf seas around the British Isles. J Geophys Res 83:4615-4622

Pingree RD, Holligan PM, Mardell GT, Head RN (1975) Summer phytoplankton blooms and red tides along tidal fronts in approaches to English Channel. Nature 258:672-677

Polovina JJ, Howell E, Kobayashi DR, Seki MP (2001) The transition zone chlorophyll front, a dynamic global feature defining migration and forage habitat for marine resources. Prog Oceanogr 49:469-483

Redfern JV, Barlow J, Bailance LT, Gerrodette T, Becker EA (2008) Absence of scale dependence in dolphin-habitat models for the eastern tropical pacific ocean. Mar Ecol Prog Ser 363:1-14

> Ross HM, Wilson B (1996) Violent interactions between bottlenose dolphins and harbour porpoises. Proc Biol Sci 263: 283-286

Russell RW, Harrison NM, Hunt GL Jr (1999) Foraging at a front: Hydrography, zooplankton, and avian planktivory in the northern Bering Sea. Mar Ecol Prog Ser 182:77-93

Scott BE, Sharples J, Wanless S, Ross ON, Frederiksen M, Daunt F (2006) The use of biologically meaningful oceanographic indices to separate the effects of climate and fisheries on seabird breeding success. In: Boyd IL, Wanless S, Camphusen CJ (eds) Top predators in marine ecosystems. Their role in monitoring and management. Conservation Biology No 12, Cambridge University Press, Cambridge

Sharples J (2008) Potential impacts of the spring-neap tidal cycle on shelf sea primary production. J Plankton Res 30:183-197

> Sharples J, Ross ON, Scott BE, Greenstreet SPR and 1 other (2006) Inter-annual variability in the timing of stratification and the spring bloom in the North-western North Sea. Cont Shelf Res 26:733-751

Simard Y, Lavoie D, Saucier FJ (2002) Channel head dynamics: capelin (Mallotus villosus) aggregation in the tidally driven upwelling system of the Saguenay-St. Lawrence Marine Park's whale feeding ground. Can J Fish Aquat Sci 59:197-210

> Simpson JH, Hunter JR (1974) Fronts in the Irish Sea. Nature 250:404-406

Sims DW, Quayle VA (1998) Selective foraging behaviour of basking sharks on zooplankton in a small-scale front. Nature 393:460-464

> Sinclair EH, Moore SE, Friday NA, Zeppelin TK, Waite JM (2005) Do patterns of Steller sea lion (Eumetopias jubatus) diet, population trend and cetacean occurrence reflect oceanographic domains from the Alaska Peninsula to the central Aleutian Islands? Fish Oceanogr 14(Suppl 1): $223-242$

Spear LB, Balance LT, Ainley DG (2001) Response of seabirds to thermal boundaries in the tropical Pacific: the thermocline versus the Equatorial Front. Mar Ecol Prog Ser 219: 275-289

> Stevick PT, Incze LS, Kraus SD, Rosen S, Wolff N, Baukus A (2008) Trophic relationships and oceanography on and around a small offshore bank. Mar Ecol Prog Ser 363: $15-28$

> Sydeman WJ, Brodeur RD, Grimes CB, Bychkov AS, McKinnell S (2006) Marine habitat 'hotspots' and their use by migratory species and top predators in the North Pacific Ocean: Introduction. Deep-Sea Res II 53:247-249

Tasker ML, Jones PH, Dixon TJ, Blake BF (1984) Counting seabirds at sea from ships: a review of methods employed and a suggestion for a standardized approach. Auk 101: $567-577$

Uda M (1952) On the relation between the variation of the important fisheries conditions and the oceanographic conditions in the adjacent waters of Japan. J Tokyo Univ Fish 38:363-389

Ware DM, Thomson RE (2005) Ecology: bottom-up ecosystem trophic dynamics determine fish production in the northeast pacific. Science 308:1280-1284

Weston K, Fernand L, Mills DK, Delahunty R, Brown J (2005) Primary production in the deep chlorophyll maximum of the central north sea. J Plankton Res 27:909-922

> Worm B, Sandow M, Oschlies A, Lotze HK, Myers RA (2005) Global patterns of predator diversity in the open ocean. Science 309:1365-1369

Yen PPW, Sydeman WJ, Hyrenbach KD (2004) Marine bird and cetacean associations with bathymetric habitats and shallow-water topographies: implications for trophic transfer and conservation. J Mar Syst 50:79-99

Zuur AF, Ieno EN, Smith GM (2007) Analysing ecological data. Springer, New York, NY 